\title{
THE IMPACT OF A PROGRAM FOR CROSSOVER YOUTH IN ONTARIO ON STAKEHOLDER COLLABORATION, KNOWLEDGE, SKILLS, AND ATTITUDES
}

A Mixed Methods Study

by

Amy Beaudry B. A.

Western University, 2016

A thesis

presented to Ryerson University

in partial fulfillment of the

requirements for the degree of

\section{Master of Arts}

in the program of

Psychology

Toronto, Ontario, Canada, 2019

(C) Amy Beaudry, 2019 


\section{AUTHOR'S DECLARATION FOR ELECTRONIC SUBMISSION OF A THESIS}

I hereby declare that I am the sole author of this thesis. This is a true copy of the thesis, including any required final revisions, as accepted by my examiners.

I authorize Ryerson University to lend this thesis to other institutions or individuals for the purpose of scholarly research.

I further authorize Ryerson University to reproduce this thesis by photocopying or by other means, in total or in part, at the request of other institutions or individuals for the purpose of scholarly research.

I understand that my thesis may be made electronically available to the public. 


\begin{abstract}
The Impact of a Program for Crossover Youth in Ontario on Stakeholder Collaboration, Knowledge, Skills, and Attitudes: A Mixed Methods Study

Master of Arts, 2019

Amy Beaudry

Psychology

Ryerson University

Crossover youth, those involved in both the child welfare and youth justice systems, are more likely to receive detention and harsher sentences than youth with no child welfare involvement. In Ontario, the Crossover Youth Project (COYP) was formed to ameliorate these systemic issues. To evaluate the success of a Toronto pilot site, a convergent parallel mixed methods study was completed. A total of 19 stakeholders, mostly from youth justice and child welfare, were interviewed at the closure of the pilot and 15 nine months later. Interviews were analyzed qualitatively using thematic analysis and interpreted alongside quantitative data from questionnaires. Themes indicate that stakeholders' knowledge of crossover youth and skills in advocacy increased, as well as their ability to collaborate. While their learning was maintained at follow-up, their ability to collaborate was impaired by loss of the case coordinator who was essential to facilitating conferences. Results can inform future interventions.
\end{abstract}




\section{Acknowledgements}

There are many people I would like to thank for assisting me throughout this intensive process. Firstly, I am grateful to my supervisor, Dr. David Day, for introducing me to this unique population and supporting my progress throughout this project. I am also indebted to our postdoctoral researcher and coordinator, Dr. Arla Good, who guided me through the qualitative analysis and was an invaluable sounding board for all my concerns. I would also like to thank my committee member Dr. Kelly McShane for linking me to resources in the qualitative area, which is far richer than I could have ever imagined. Also, Carson Pun, for his help repeatedly reconnecting me to our lab drive when my laptop broke down.

And finally, I would not have made it through without the support of my lab members, particularly Sofija Lavrinsek, my constant comrade. 
Table of Contents

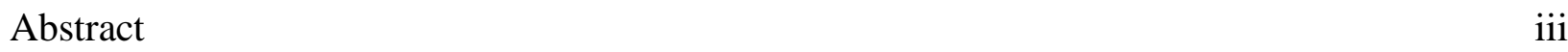

List of Tables

$\begin{array}{ll}\text { List of Figures } & \text { ix }\end{array}$

List of Appendices $\quad$ X

Introduction $\quad 1$

$\begin{array}{lr}\text { Crossover Youth } & 2\end{array}$

Characteristics of Crossover Youth $\quad 5$

$\begin{array}{ll}\text { Systemic Biases Against Crossover Youth } & 6\end{array}$

The Role of Stakeholders and Service-Providers in the Care of Crossover Youth 8

$\begin{array}{ll}\text { Interventions for Crossover Youth } & 9\end{array}$

$\begin{array}{ll}\text { Project Confirm. } & 9\end{array}$

Crossover Youth Practice Model. $\quad 11$

Intervention in Toronto: The Cross-over Youth Project 14

The Present Study: Stakeholder Views of the Cross-over Youth Project 16

$\begin{array}{ll}\text { Methods } & 17\end{array}$

$\begin{array}{ll}\text { Participants } & 17\end{array}$

$\begin{array}{ll}\text { Stakeholder and organization characteristics. } & 17\end{array}$

$\begin{array}{ll}\text { Materials } & 22\end{array}$

$\begin{array}{ll}\text { Interview guide. } & 22\end{array}$

$\begin{array}{ll}\text { Stakeholder collaboration. } & 22\end{array}$

$\begin{array}{ll}\text { Service provider skills and attitudes. } & 23\end{array}$

$\begin{array}{ll}\text { Procedure } & 25\end{array}$ 
$\begin{array}{ll}\text { Results } & 30\end{array}$

$\begin{array}{ll}\text { Qualitative Analysis } & 30\end{array}$

Research Question \#1: Themes relevant to stakeholder collaboration. 30

Barriers for youth. $\quad 30$

Program implementation. $\quad 32$

Barriers to implementation. $\quad 34$

Program outcomes: Collaboration. 36

Program recommendations. $\quad 36$

Research Question \#2: Themes relevant to stakeholder knowledge, skills, and attitudes. 38

$\begin{array}{ll}\text { Barriers for youth. } & 38\end{array}$

$\begin{array}{ll}\text { Program implementation. } & 39\end{array}$

Barriers to implementation. $\quad 40$

$\begin{array}{ll}\text { Program outcomes. } & 41\end{array}$

Recommendations: Education. $\quad 42$

Research Question \#3: Themes relevant to sustainability. 43

Loss of case coordinator. $\quad 43$

Loss of case conferencing. $\quad 44$

Maintained knowledge, skills, and attitudes. $\quad 44$

Possible sustainability planning.

$\begin{array}{ll}\text { Quantitative Analysis } & 45\end{array}$

$\begin{array}{ll}\text { Stakeholder collaboration. } & 45\end{array}$

$\begin{array}{ll}\text { Stakeholder and innovation characteristics. } & 48\end{array}$ 
$\begin{array}{ll}\text { Discussion } & 51\end{array}$

Research Question \#1 52

Research Question \#2 53

Research Question \#3 55

Significance of Findings for Future Intervention 56

$\begin{array}{ll}\text { Limitations } & 58\end{array}$

$\begin{array}{ll}\text { Future Directions } & 60\end{array}$

$\begin{array}{ll}\text { Appendices } & 61\end{array}$

$\begin{array}{ll}\text { References } & 82\end{array}$ 


\section{List of Tables}

Table $1 \quad$ Stakeholder Characteristics at Time 1 and Time 2 Interviews....................19

Table 2 Organization Characteristics at Time 1 and Time 2 Interviews.................21

Table 3 Measure of Service Integration - Subscale Means and Reliability Coefficients Across Time Points...................................................................................................46

Table 4 Reliability Coefficients for all Stakeholder and Innovation Characteristics Subscales..............................................................49

Table 5 Mean Scores for Stakeholder and Innovation Characteristics...................51 


\section{List of Figures}

Figure $1 \quad$ Mean service integration across two time points............................47

Figure 2 Mean stakeholder and innovation characteristics regarding meeting needs across two time points.....................................................50

Figure 3 Mean stakeholder and innovation characteristics regarding supporting rights across two time points...........................................50 


\section{List of Appendices}

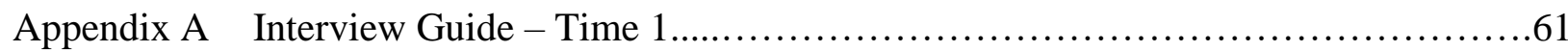

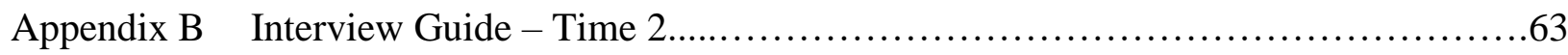

Appendix C Stakeholder and Organizational Information Form $\ldots \ldots \ldots \ldots \ldots \ldots \ldots \ldots \ldots \ldots . \ldots 6$

Appendix D Measure of Service Integration.......................................68

Appendix E Service Provider Adopter and Innovation Characteristics Questionnaire.........72

Appendix F Recruitment Letter............................................. 75

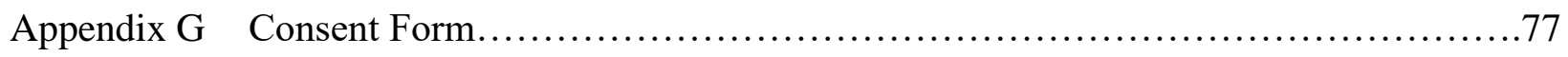




\section{Introduction}

As of March 31, 2013, 62428 children - approximately 8.5 in every 1000 - were living in out-of-home care across Canada, a number that has been relatively steady since 2004 (Jones, Sinha, \& Trocmé, 2015). According to the Ontario Incidence Study of Reported Child Abuse and Neglect, which tracked the activities of the 46 in-province child welfare agencies at the time, there were 95951 investigations of possible child maltreatment over the course of three months in 2013, 44 percent of which were substantiated (Fallon et al., 2015). The youth justice system in Ontario, which provides services to youth ages 12 to 17 , has been experiencing a downward trend in the number of supervised youth since 2010 (Malakieh, 2017). Despite this decrease, an average of 8455 youth were supervised each day in Canada between 2015 and 2016 (Malakieh, 2017). Though there are no data on how many children move between the child welfare and

youth justice systems in Ontario, research outside of Ontario indicates that somewhere between 2 and 73 percent of youth with child welfare involvement will also have contact with the youth justice system (Halemba, Siegel, Lord, \& Zawacki, 2004; Huang, Ryan, \& Herz, 2012; TurpelLafond, \& Kendall, 2009; Stewart, Dennison, \& Waterson, 2002; Vidal et al., 2017), becoming "crossover youth."

Crossover youth are a vulnerable population composed of a disproportionately high number of racial minorities (Lee \& Villagrana, 2015; Ryan, Herz, Hernandez, \& Marshall, 2007) and LGBTQ youth (Irvine \& Canfield, 2016). Crossover youth typically have high educational needs (Halemba et al., 2004) and high rates of mental health and substance use issues (Halemba et al., 2004; Turpel-Lafond \& Kendall, 2009). They also face systemic barriers within the justice system, including harsher sentences and greater likelihood of detention as compared to noncrossover youth (Conger \& Ross, 2001; Ryan et al., 2007). Interviews with stakeholders in 
Ontario suggest that a lack of coordinated care and other system-wide issues prolong the involvement of crossover youth in the justice system (Bala, Finlay, De Filippis, \& Hunter, 2015). Fortunately, programs such as the Cross-over Youth Project in Ontario have been developed to ameliorate these systems-level issues and improve outcomes for these youth through a variety of avenues, including greater system integration between child welfare and youth justice and service provider education (Scully \& Finlay, 2015). However, the short and long-term impact of the Cross-over Youth Project on stakeholders caring for crossover youth - including service providers in the education, child welfare, mental health, and youth justice systems - is currently unknown. This thesis will expand on the above issues and present the results of a study to examine the effect of the Toronto site of the Cross-over Youth Project on stakeholder collaboration, knowledge, skills, and attitudes, as well as the sustainability of these changes.

\section{Crossover Youth}

Many terms have been used to describe youth who have experienced maltreatment and committed delinquent acts, including both youth who have and youth who have not been processed by the child welfare and youth justice systems. Herz, Ryan, and Bilchik (2010) penned the most widely-accepted definitions, which have been utilized in the social work (e.g., Huang, Ryan, Sappleton, \& Chui, 2015; Kolivoski, Goodkind, \& Shook, 2017; Lee \& Villagrana, 2015), psychology (e.g., Baetz, 2017), and criminology (e.g., Baglivio et al., 2016) literatures. According to Herz and colleagues' taxonomy, dually involved youth are those who are concurrently involved, even peripherally, in both the child welfare and the youth justice systems. A subset of dually involved youth can be called dually adjudicated youth, who are formally involved in each system at the same time. Several other terms have been used interchangeably in the literature, including dual jurisdiction youth and dually-served youth (Baglivio et al., 2016; 
Halemba et al., 2004). All of these groups fall under the umbrella term crossover youth, which broadly includes any youth who have both experienced maltreatment and exhibited delinquency at some point during development but have not necessarily had child welfare or juvenile justice system involvement (Herz et al., 2010). Though the term implies that youth are "crossing over" from earlier child welfare involvement or maltreatment to later youth justice involvement or delinquency, there is no necessary temporal relationship between the two experiences. There are multiple pathways to becoming a crossover youth: contact with the child welfare system followed by later contact with the youth justice system, while still in care; past involvement with the child welfare system and later contact with the youth justice system, after leaving care; contact with the youth justice system leading to an investigation by child welfare; and lastly, entrance into the child welfare system after being detained by the justice system when they have nowhere to return to upon release (Herz et al., 2010). Nonetheless, for the vast majority of crossover youth, child welfare system involvement precedes contact with the youth justice system (Huang et al., 2012).

The proportion of child welfare-involved youth who subsequently become crossover youth varies widely across studies. This discrepancy likely depends largely on the location the study was conducted, as differences in local legislation and policy can greatly affect the treatment of crossover youth. Interviews with a sample of 148 justice-involved youth across Canada found that half self-reported past child welfare involvement (Finlay, 2012), while in a study of the family court in London, Ontario, the number was as high as $84.3 \%$ (Stewart, 2018). In their cohort study of British Columbian youth born in 1986, Turpel-Lafond and Kendall (2009) found that 35 percent of child welfare-involved youth subsequently became formally involved with the youth justice system, a percentage much greater than the 6.6 percent for non- 
welfare-involved youth. While there is no equivalent cohort study for Ontario, in Kitchener and Waterloo approximately 17 percent of children on probation in 2010 were involved with local child welfare, compared to less than 1 percent of the general child population (Piscitelli \& Follett, 2012). Some American studies report relatively lower rates of cross over into the justice system.. In Los Angeles, Huang and colleagues (2012) examined the records of a cohort of youth involved with child protection services and found that only 2.3 percent had juvenile records during the period of the study (which was at least five years after their child welfare involvement). Vidal and colleagues (2017) found a similarly low estimate of 2.5 percent in their prospective study of maltreated youth in Rhode Island. By contrast, the findings of the Arizona Dual Jurisdiction Study returned much higher rates of dual involvement, depending on the age of the youth (Halemba et al., 2004). For the 5093 youth who had open child welfare cases between July 2001 and June 2002 in four Arizona counties, referrals to the delinquency court occurred for 14 percent of 8 to 10-year-olds, 43 percent of 11 to 13 -year-olds, and 73 percent of 14 to 17 year-olds. Findings from the 1983 birth cohort in Queensland, Australia, suggest an intermediate 16 percent of child welfare-involved youth subsequently became crossover youth (Stewart et al., 2002).

With respect to why this cross over to the justice system occurs, research has consistently shown that maltreatment during childhood is related to later delinquent behaviour (Ryan \& Testa, 2005; Stouthamer-Loeber, Wei, Homish, \& Loeber, 2002; Widom, 1989). From a theoretical perspective, this is intuitive. Moffitt's (1993) theory of life-course persistent offending suggests that underlying developmental deficits combined with a triggering environment produce long-term antisocial behaviour. Widom's (1989) “cycles of violence" hypothesis suggests that exposure to parental aggression and antisocial behaviour as a child 
predisposes those children to elicit similar aggressive and antisocial behaviours in adulthood. Indeed, crossover youth in Arizona were typically found to have troubled family relationships, with just over two thirds of youth reporting that they had observed problematic substance use by a parent, and half of youth having at least one parent with a history of incarceration (Halemba et al., 2004).

\section{Characteristics of Crossover Youth}

Samples of crossover youth differ from the general youth population, and even from youth justice populations, with respect to racial composition, sexual orientation and gender expression, age at first offence, mental health needs, and educational needs. In American crossover samples, black youth are overrepresented (Ryan et al., 2007). For example, Lee and Villagrana's (2015) juvenile justice sample was 21 percent black, while black youth made up 41 percent of their crossover sample. In Canada, black youth are also overrepresented, but there is additional focus on the overrepresentation of Indigenous youth as well (Turpel-Lafond \& Kendall, 2009). Non-heterosexual and non-gender conforming youth are also overrepresented in crossover populations (Irvine \& Canfield, 2016).

There is some evidence that crossover youth become entangled in the justice system at a younger age than youth not in the child welfare system (Halemba et al., 2004; Ryan et al., 2007), though the differences in age at first justice system contact are small: 0.2 years younger in Lee and Villagrana's (2015) study and 0.6 years younger in Ryan et al.'s (2007). Difficulties with substance use and mental health also are prevalent in crossover samples (Turpel-Lafond \& Kendall, 2009). Halemba and colleague's (2004) case-file review revealed that 80 percent of their crossover sample had problematic substance use, while 61 percent had serious psychopathology. Finally, crossover youth typically have very low educational attainment. The 
majority of Halemba et al.'s (2004) sample had difficulties with truancy and schoolwork. One particularly alarming finding of Turpel-Lafond and Kendall's (2009) cohort study in British Columbia was that child welfare-involved youth were more likely to become involved with youth justice than to graduate high school - once the youth in the study crossed over, only 13 percent graduated high school. In summary, crossover youth are a highly vulnerable population with complex risks.

Crossover youth also experience poor criminal justice outcomes. Halemba and colleagues (2004) found that crossover youth in Arizona had double the recidivism rates of comparison youth who were only justice-involved. Similarly, Lee and Villagrana (2015) found that after a first arrest, crossover youth were more likely to be arrested on a subsequent occasion than justice-involved, non-child welfare-involved youth.

\section{Systemic Biases Against Crossover Youth}

Beyond the issues that crossover youth face at home and at school, several studies have found system-wide judicial practices that may further disadvantage crossover youth. Research in Los Angeles by Ryan and colleagues (2007) indicates that, although crossover youth are equally likely to have their case dismissed for their first arrest, they are less likely to receive probation the common alternative to placement, which entails a stay in a group home or correctional facility - when compared to youth without historical child welfare involvement and when matched on race, sex, and type of offense using propensity score matching. These sentencing differences may represent biases on the part of judges; however, they may also reflect that at the time of crossing over, youth can lose their existing placement or not have a suitable placement available, and so judges may believe the only viable option is to shunt the youth further into the justice system (Tam, Abrams, Freisthler, \& Ryan, 2016; Ryan et al., 2007). Similarly, crossover 
youth in New York awaiting trial were more likely to be held in pre-trial detention than to be sent home, compared to solely justice-involved youth, regardless of the severity of their offence (Conger \& Ross, 2001).

The deeper justice system involvement that such sentencing and detention practices produce is problematic in part because it is hypothesized to exacerbate existing behavioural issues. One proposed mechanism for this phenomenon is peer contagion: when in congregate or correctional care, youth are exposed to peers who exhibit a variety of delinquent behaviours (Dishion \& Dodge, 2005). Another problem is that such institutionalization can lead youth to be stigmatized (Bala et al., 2015; Chapin \& Griffin, 2005). Similarly, the placement of crossover youth in more restrictive placements may lead to the accumulation of additional charges. Change of placement after arrest, particularly to a more restrictive environment such as a group home, is associated with greater recidivism (Huang et al., 2015). Research also indicates that the type of placement predicts caregiver-reported delinquency, with the lowest scores being in kinship care, and the highest in group homes (Farineau \& McWey, 2011). While this finding may result from youth with more severe behavioural issues being placed in more secure environments, it is theorized that more restrictive placements produce more opportunity for rule violations, which leads to conflict and subsequent arrest, as structured environments are more likely to involve the police for minor rule violations (Tam et al., 2016). Consistent with these findings, approximately half of offences committed by crossover youth in the British Columbia cohort study were administrative, such as staying out past curfew, or breaching probation or bail conditions (Turpel-Lafond \& Kendall, 2009).

Though comparable empirical research does not exist in Ontario, the above findings are consistent with observations made by workers in the Ontario youth justice system (Bala et al., 
2015). Interviews with 22 stakeholders - including youth court judges, lawyers, probation officers, youth workers, and mental health professionals - indicate that there is a perceived need to decrease the reliance on the justice system when dealing with crossover cases and to increase the integration of services provided by the child welfare and youth justice systems (Bala et al., 2015). Group homes, utilized as a placement for children removed from foster care due to behavioural issues, are seen as a breeding ground for charges, as police are frequently called by staff for minor rule violations (Bala et al., 2015; Finlay, 2007). Consistent with this perception, the police department in Trent Hills, Ontario, organized a community meeting to raise the issue of excessive group home reliance on police intervention for non-criminal acts by youth (Hoult, 2012). Case studies also indicate that the bail conditions placed on crossover youth are often unreasonably vague, such as not being "verbally abusive" (Bala et al., 2015).

\section{The Role of Stakeholders and Service-Providers in the Care of Crossover Youth}

As crossover youth have extensive contact with a variety of health, educational, and social systems due to their high needs, stakeholders and service providers need training in order to reduce bias, as well as a greater ability to collaborate to both identify crossover youth and better serve crossover youth. Fundamentally, improving the care and reducing systemic biases against crossover youth requires the engagement of the service providers and stakeholders who are responsible for them, which includes those in the education system (teachers, principals, etc.), child welfare system (group home staff, foster parents, case workers, etc.), mental health system (psychological, psychiatric, court mental health workers, etc.), and youth justice system (police, defence lawyers, crown attorneys, etc.). The above systemic issues may reflect a lack of training on the needs of this niche population, resulting in biases against them on the part of the many stakeholders involved in their care (Conger \& Ross, 2001; Tam et al., 2016; Ryan et al., 
2007). Education and professional training are considered critical to enhancing the stakeholders' knowledge of crossover youth and the barriers they face, reducing biases, and providing skills for working with them (Gallegos \& Roller White, 2007).

The ability of stakeholders to identify and understand crossover cases may also depend on collaboration among the many systems in which they are involved. Collaboration - which is itself a complex concept - ranges on a continuum from the level of communication (e.g., basic information sharing) to the level of integration (e.g., combination of previously separate organizations), and has been widely touted as a goal of services for children and youth (Horwath \& Morrison, 2007). In particular, collaboration is viewed as a way to prevent child welfareinvolved youth from crossing over to youth justice (Gallegos \& Roller White, 2007) through the creation of collective, coordinated plans (Bala et al., 2015). Broadly speaking, integrated services improve the care of high needs youth receiving diverse social services within both the youth justice and child welfare systems. Indeed, Farrell, Young, and Taxman (2011) found that integration between a state's juvenile justice agencies and community agencies - in the form of information and resource sharing, and visible coordination - was associated with researchsupported practice.

\section{Interventions for Crossover Youth}

In the following section, two interventions in the US that targeted service provider education and collaboration will be described.

Project Confirm. Beginning in 1998, a partnership between the Vera Institute of Justice and eight agencies in New York led to the launch of Project Confirm (Conger \& Ross, 2001; Conger \& Ross, 2006). The purpose of the initiative was to target the disproportionate use of pretrial detention for youth in foster care, compared to youth residing with family members (Conger 
\& Ross, 2001). This discrepancy was of concern due to financial costs and costs to youth (e.g., psychological, educational, loss of placement; Conger \& Ross, 2001; Conger \& Ross, 2006). Judges' decisions were generally considered the result of a lack of "release resource" during court appearance; the lack of an advocate, such as a parent, due to service providers' confusion about roles; and the lack of appropriate information exchange (Conger \& Ross, 2006; Ross, Conger, \& Armstrong, 2002). One barrier for youth in general was the large number of disconnected service providers involved in their care; professionals had little knowledge of each other's roles and there was little information exchange (Conger \& Ross, 2001; Ross et al., 2002).

Project Confirm's activities entailed: 1) notification of the child welfare case worker that a representative was legally required at the youth's first hearing, and 2) conferencing between child welfare case workers and Project Confirm field coordinators, in addition to others involved in the youth's care, to increase understanding of roles and allowing information sharing between key players (Conger \& Ross, 2001; Conger \& Ross, 2006; Ross et al., 2002). There were also educational events held by the project staff to assist child welfare case workers and managers in understanding and navigating the youth justice system (Conger \& Ross, 2001). Additionally, project staff were considered a neutral party for all players to use as an informational resource (Conger \& Ross, 2001). The intended outputs and outcomes included greater service provider knowledge, greater information sharing, decreasing the pre-trial detention discrepancy, reducing placements changes, and reducing the use of emergency placements (Conger \& Ross, 2001). A random survey of 40 front-line service providers as well as management indicate that they perceived the intervention as worthwhile and helpful, and viewed the field coordinators very positively (Ross et al., 2002). The vast majority viewed the program as facilitating communication between the child welfare and youth justice systems (Ross et al., 2002). 
Notification was successful in getting case workers to court in approximately 75 percent of cases, which increased to 93 percent when combined with the field coordinators, who were suspected to increase the case workers' confidence in attending court (Ross et al., 2002). Barriers to a complete implementation - that is, the integration of the program into everyday practice were considered staff turnover (and thus the need to train every case worker), the need for identification of crossover youth without Project Confirm staff, and the general challenges of implementing a program requiring cooperation from multiple sectors (Ross et al., 2002). Resistance was expected, as the program required front-line workers to change their everyday practice (Ross et al., 2002). In spite of this, the program was largely successful due to the program's ability to have supervisors inform and then mandate changes, as well as repeated efforts to educate front line workers through the posting of reminders in their work spaces, addition of the project's procedures to manuals and orientation materials, and measurement of compliance (Ross et al., 2002).

With respect to outcomes of the project, for lesser offenses, and for youth with no prior justice system involvement, the activities of the project significantly reduced the pre-trial detention bias against child welfare-involved youth (Conger \& Ross, 2001; Conger \& Ross, 2006). However, the intervention was not successful for those with serious offenses, and actually increased the discrepancy, suggesting that the information shared by case workers in court (e.g., past absences without leave) was not helpful in those cases and created further bias (Conger \& Ross, 2001; Conger \& Ross, 2006).

Crossover Youth Practice Model. The Crossover Youth Practice Model (CYPM), an ideological framework for systemic changes in service provision to crossover youth, was developed at the Center for Juvenile Justice Research (Stewart, Lutz, \& Herz, 2010; Haight, 
Bidwell, Choi, \& Cho, 2016). The system, which aims to orient siloed youth justice and child welfare services to a consistent philosophy around the treatment of crossover youth, has been widely implemented in the United States (cjjr.georgetown.edu/our-work/crossover-youthpractice-model; Stewart et al., 2010). Overall, the general goal of the model is to decrease the involvement of crossover youth in the justice system (Stewart et al., 2010). Implementation focuses on increasing inter-sectoral communication and collaboration, particularly between youth justice and child welfare, as well as interventions for individual youth and their families (Haight et al., 2016). Participation of the youth's family (e.g., foster parents, community group members) is considered a fundamental component of the CYPM (Haight et al., 2016). Desired outcomes affect many aspects of crossover youths' care, including housing (e.g., lower rates of congregate care usage), justice (e.g., lower rates of pre-trial detention, recidivism), as well as aspects of service provision (e.g., greater information sharing; Stewart et al., 2010; Haight et al., 2016).

The CYPM requires collaboration amongst service providers involved in crossover youths' care, including education (i.e., teachers), lawyers, and mental health professionals (Stewart et al., 2010). Prior to implementation of the CYPM in a county, cross-sectoral training of service providers is conducted by credible sources (e.g., figures in service providers' fields) to enable them to understand the intervention, as well as the roles and processes relevant to crossover youths' care outside their field (Stewart et al., 2010). These educational efforts occur regularly (i.e., every few months) prior to and throughout implementation of the CYPM (Stewart et al., 2010; Haight et al., 2014).

As outlined in Stewart et al. (2010) and Haight et al. (2016), implementation of the CYPM is considered a three-phase process. In the first phase, crossover youth are identified, 
typically during intake into detention, after which the child welfare worker is contacted and required to attend the youth's court hearing (as in Project Confirm). This process requires a memorandum allowing for information exchange between the two systems, a screening tool, and protocols for searching databases for youth. When appropriate, diversion is pursued. In cases where diversion does not occur, the second phase begins, during which a joint assessment is completed between agencies, and team meetings are held with the youth's family and case workers from both systems. The purpose of these meetings is to collaboratively plan for the youth's care (e.g., placement decisions and referrals to other services in the community). Courts are recommended to implement one of the following models to facilitate this: 1) specialized crossover youth court; 2) two-hatter judge who presides over both the child welfare and youth justice proceedings; or 3) case conferencing prior to court in order to present a single, unified plan. In the third phase, the same team coordinates a long-term care plan, to ensure a successful transition for the youth.

In order to evaluate professionals' response to such a demanding intervention, Haight, Bidwell, Marshall, and Khatiwoda (2014) interviewed 84 service providers from five counties implementing the CYPM in the United States. Results suggest that professionals viewed the change process in a variety of ways, including as a "culture shift" or a more step-by-step process of aligning their agency's philosophy with that of the CYPM. Stakeholders also noted less service duplication and greater access to services, as well as protocols for greater information sharing. Other positive changes were noted in understanding and relating to other professions. However, there were also barriers to change, including a lack of training, lack of resources, challenges understanding the CYPM model and the role to be played by each professional, and lack of buy-in. With respect to a quantitative evaluation of the outcome data, when comparing 
youth receiving CYPM services in a single county to historical and contemporaneous samples, results indicate that the intervention decreased recidivism rates for crossover youth (Haight et al., 2016).

\section{Intervention in Toronto: The Cross-over Youth Project}

Though both the CYPM and Project Confirm were assessed as successful, they cannot be directly replicated in the Canada due to differences in our child welfare and youth justice systems. Therefore, in response to the aforementioned systemic issues, the Cross-over Youth Project (COYP) was formed in Ontario with funding from the Department of Justice Canada and the former Ministry of Children and Youth Services. The COYP was developed to ameliorate the systemic barriers crossover youth face, improve their care by facilitating service provision, and prevent their entrenchment in the youth justice system through the combined effects of restrictive placements, unrealistic bail conditions, and a lack of coordinated care (Scully \& Finlay, 2015). Many pillars were identified as components of the project's mandate, but there was a particular focus on youth's rights and rights guiding principles (Cross-Over Youth Project, 2016) and, increasingly over the course of the project, trauma-informed practice (Finlay, 2018). The activities and goals of the project were informed by key stakeholder groups who joined to form a steering committee, including police, judges, legal services (e.g., defence counsel), justices of the peace, child welfare, group home workers, crown attorneys, and the crossover youth themselves. This consultation identified a variety of activities and goals for the program: 1) greater collaboration and communication between the child welfare and youth justice systems (despite different mandates); 2) preventing contact of youth in care with the justice system or minimizing time spent there; 3) cross-sectoral education and training; 4) protocols for attainable and relevant bail conditions; 5) protocols for charging in congregate care; 6) clarity regarding the role of child 
welfare in court; 7) educating and utilizing legal system actors with knowledge of both family and justice systems ("two-hatter"); 8) employing designated court workers with expertise in child welfare and youth justice to facilitate information exchange; 9) education planning for crossover youth; 10) investigating alternatives to congregate care; and 11) developing a mentorship program for youth (Scully \& Finlay, 2015).

With these goals and activities in mind, the COYP launched its first pilot site in Toronto in March 2016 at the specialized 311 Jarvis youth courthouse, where the project was sustained until it formally ended in December 2017. In practice, the project operated at multiple intervention points in order to achieve its disparate goals. A case coordinator (at times referred to as a Case Conference Facilitator in project documentation) was hired by the project, attended bail court to identify crossover cases and offered them services from the COYP. If the youth accepted, the case coordinator advocated for the youth, acted as a liaison between systems, referred the youth to relevant diversion programs, and organized case conferences involving key actors in the youth's care (Cross-Over Youth Project, 2016). As of the end of the pilot, 57 youth had received services. Less directly involved with the care of the youth, but no less important, a resource coordinator aimed to change and inform policies and practices relevant to crossover youth that were identified by the case coordinator and the steering committee. The case conference facilitator and resource coordinator were also understood to be an educational resource for the service providers working directly with the youth (Cross-Over Youth Project, 2016). Additional activities of interest were undertaken by sub-committees of the steering committee, such as developing a best practices manual for use in the child welfare system, hosting an education day for relevant stakeholders, and training "two-hatter" lawyers in both child welfare and youth justice so that crossover cases could be represented by a single lawyer. 


\section{The Present Study: Stakeholder Views of the Cross-over Youth Project}

As of the end of the COYP in 2017, it was unknown whether the Toronto site produced greater collaboration or enhanced stakeholders' knowledge, skills, and attitudes towards their vulnerable crossover clients. Additionally, since the project was a pilot, and direct services were phased out of the youth court at 311 Jarvis in spring of 2018, it was also unclear whether any desired outcomes were maintained over time. As many of the program's activities required either the active participation of service providers (e.g., cross-sectoral education and training) or execution by service providers (e.g., greater collaboration and communication), evaluating the program required consultation with these stakeholders, as was completed by Haight and colleagues (2014) for the CYPM. Thus, the present convergent parallel mixed methods study (Creswell, 2014) was completed as a component of a larger evaluation of the overall COYP. There were 19 stakeholders from various professional backgrounds interviewed at Time 1, occurring between one to four months after the formal end of the COYP, about their general perceptions of the program, as well as their views of its success in achieving the overarching goals of intersectoral contact and collaboration, and enhanced stakeholder knowledge, skills, and attitudes. There were then 15 stakeholders interviewed at Time 2, occurring between 11 and 15 months after the formal end of the COYP, as a follow-up to the initial interviews to assess any sustained impact. At both time points, the participating stakeholders completed several questionnaires assessing their views of the project's directive and their collaboration. Overall this study aimed to answer the following research questions: 1) How did the COYP affect service integration?; 2) How did the COYP affect stakeholder knowledge, skills, and attitudes towards crossover youth?; and 3) Were the changes in service integration, and stakeholder skills, knowledge, and attitudes sustained in the year following the end of the pilot? 


\section{Methods}

\section{Participants}

Participants were service providers who worked directly with crossover youth, those who were intended to benefit from the COYP, and those who were involved in the implementation of the COYP. Based on those criteria, potential participants included the following stakeholder groups: 1) police, 2) justice system representatives (crown attorneys, defence attorneys, judges, justices of the peace), 3) probation services, 4) community agencies serving crossover youth, 5) child welfare services, 6) mental health services, 7) employees at the Ministry of Children, Community, and Social Services (MCSS), and 8) group home workers. Given that there are thousands of people within these stakeholder groups in the city of Toronto, recruitment was limited to those who had come into contact with the COYP throughout the course of their work or involvement in its implementation. Given the definition of a population in advance, the sampling is considered statistical (Flick, 2014).

A total of 22 stakeholders were interviewed, 19 at Time 1 and 15 at Time 2. Of those interviewed at Time 1, 12 returned at Time 2 for their second interview, with an overall attrition rate of 31 percent. Reasons for attrition were coded by the author as: left original position $(n=4)$ and no response to follow-up invitation $(n=3)$. Three of the interviewees at Time 2 had not been interviewed at Time 1.

Stakeholder and organization characteristics. The Stakeholder and Organizational Information Form, adapted by Day and colleagues (2016), was used to collect information on participant characteristics to ensure representation by relevant stakeholder groups (see Appendix C). Of note, only 12 participants opted to complete the form at Time $1(63 \%)$ and 11 at Time 2 
(73\%), so the characteristics of approximately one third of participants and their organizations are unknown.

Participants came from a variety of positions, professional backgrounds, and service sectors (see Table 1). The vast majority of the participants at both time points considered themselves direct service providers or belonging to a group other than executive director and program manager. At both time points there was a wide range in the number of years that participants had held their position, as well as their years of experience with youth. The most frequently selected professional background was law ( $n=6$ at Time $1, n=7$ at Time 2), followed by social work ( $n=3$ at Time $1, n=2$ at Time 2 ), with single participants selecting other fields. There were no participants who considered their background as "addictions." All participants had at least a college diploma, with the majority having either a master's degree ( $n=6$ at Time 1 , $n=3$ at Time 2 ) or a J.D. ( $n=5$ at each of Time 1 and Time 2, respectively). Generally, participants felt they had some influence over decisions about youth in their role $(M=5.17$ at Time $1, M=5.55$ at Time 2). 
Table 1

Stakeholder Characteristics at Time 1 and Time 2 Interviews

Time 1

Time 2

Frequency OR $M(\mathrm{SD})$

Frequency OR $M(\mathrm{SD})$

$\mathrm{N}$

19

15

Current position

Executive Director

0

0

Program Manager

0

Direct Service Provider

Other

Did not specify

4

8

7

2

2

7

4

Years in position

$13.38(15.49)$

$10.80(11.19)$

Years of experience with youth

$17.07(14.25)$

$12.64(7.58)$

Professional background

Addictions

0

Education

Nursing

Medicine

Social work

Psychology

Sociology

Law

Child and Youth

Other

Did not Specify

1

1

1

3

1

1

6

1

3

5

0

1

0

0

2

1

0

7

1

1

4

Highest level of education

High school diploma

College Diploma

Bachelor's

Master's degree

J.D

Ph.D.

Other

Did not specify

0

1

2

6

5

0

1

4

0

1

2

3

5

0

0

4

Influence over decisions

$5.55(0.82)$

Note: Influence over decisions item was rated on a scale of 1 (Not at all) to 7 (Completely). 
The characteristics of the stakeholders' organizations can be found in Table 2.

Participants were predominantly from organizations within the child welfare ( $n=4$ at Time $1, n$ $=6$ at Time 2 ), youth justice ( $n=5$ at Time $1, n=3$ at Time 2$)$, and children's mental health sectors ( $n=2$ at Time $1, n=3$ at Time 2 ). There was no representation of addictions, health, or housing/shelter organizations at either time point. Services offered by the organizations were widespread, with the most commonly identified being legal services $(n=4$ at Time $1, n=8$ at Time 2) and case management ( $n=5$ at both time points). The majority of the organizations serviced youth in the 12 to 15 and 16 to 20 age groups. They were almost evenly split on whether they provided services to family members. Though some agencies were small $(n=4$ at both time points), the remainder were large ( $n=7$ at both time points). Affiliation with a university varied across time points - more participants reported their organizations were affiliated at Time $2(n=$ 7) than Time $1(n=3)$. 
Table 2

Organization Characteristics at Time 1 and Time 2 Interviews

Time 1

Time 2

Frequency

Frequency

$\mathrm{N}$

19

15

Primary service sector

Addictions

0

Child Welfare

4

Children's Mental Health

2

Health

Housing/Shelter

0

0

Youth Justice

5

Other

Did not specify

Services offered by organization

Health Care

Legal Services

Assessment/Consultation

Case Management

Outpatient treatment

Day treatment

Inpatient/Crisis Beds

Withdrawal Management

Residential Treatment

Individual therapy/counselling

Group treatment

Family therapy

Recreational programs

Housing support

Educational programming

Other

Did not specify

Age groups serviced

$$
\begin{aligned}
& 0-5 \\
& 6-11 \\
& 12-15 \\
& 16-20 \\
& 20-25
\end{aligned}
$$

Did not specify 
Services for family members

Yes

No

Did not specify

Size of agency

Small ( $\leq 10$ full time)

Medium (11 - 30 full time)

Large ( $\geq 31$ full time)

Did not specify

Academic affiliation

Work with people from a university or college

We are in the same community as a university or college

There is no university or college in our community

Other

Did not specify

2

3

9

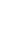


The Time 2 interview acted as a follow-up to examine which, if any, positive outcomes of the project had been maintained in the nine months since the initial interview (see Appendix B). Some questions remained largely the same with the addition of statements to clarify the time period being referred to (e.g., "over the past nine months"). However, additional COYP activities not outlined in early program documents became apparent in the first set of interviews (e.g. best practice protocols for child welfare workers), and as such additional prompts were added to the first question. During the first round of interviews, participants also had significant difficulty understanding and responding to the question on race and diversity ("Has race/diversity and racism influenced the experience of staff and youth in the program?"), so it was rewritten ("Do you believe that race and racism play a role in the systemic experiences of racialized crossover youth in your sector? Do you believe that the COYP played a role in explicitly addressing racism?"). Items 9 and 10 from the first interview assessing the indirect and direct impact of the program resulted in largely redundant answers and so were combined into a single question. Finally, supplemental questions on the sustainability of the program were added (e.g., "What changes to the treatment of crossover youth as a result of the COYP have been sustained since the withdrawal of dedicated staff from 311 Jarvis? What changes haven't been sustained?').

Stakeholder collaboration. The Measure of Service Integration is a 17-item questionnaire, adapted from an evaluation of a fire-setting program by Henderson and colleagues (Henderson, MacKay, \& Peterson-Badali, 2010) and originally modeled after work by Baker and Perkins (1984). The measure assesses overall collaboration, as well as the extent of collaboration between the interviewee and various other services relevant to crossover youth's care (see Appendix D). Because of the program's overall goal of meeting the needs of crossover youth, and the program's mandate of supporting rights of the youth, the measure was split to assess 
collaboration for both those purposes. The first 6 questions make up the subscale on inter-agency collaboration for the purpose of meeting crossover youth needs, assessing the importance of contact (e.g., "During the past 6 months, local partners were important in meeting the needs of my crossover youth clients"), frequency of contact (e.g., "During the 6 past months I frequently had contact with people from local partners who provide services to meet the needs of my crossover youth clients."), and reciprocal nature of contact (e.g., "My agency influenced the services or operations of local partners to meet the needs of my crossover youth clients."). The first six questions are rated on a 7-point Likert scale ranging from Strongly Disagree to Strongly Agree. Seven parallel questions are asked in the second section of the questionnaire, with a focus on the supporting the rights of the youth. Five additional questions on the frequency of contact, split by agency (addictions, child welfare, children's, mental health, housing/shelter, youth justice) are rated on a 7-point Likert scale from 1 (Not at all) to 7 (Often), to create sub-scores for collaboration with each service sector. Past research utilizing the total score of a variant of the measure found it to have a Cronbach's alpha of 0.90 (Henderson, 2003).

Service provider skills and attitudes. The Service Provider Adopter and Innovation Characteristics Questionnaire (see Appendix E) was adapted from Henderson and colleague's (2006) paper on the factors related to the implementation of an intervention program for youth fire-setting. As in the previously described measure, the first section of the questionnaire is on Addressing Needs, and includes questions about attitudes regarding the necessity of addressing crossover youth needs, making up the Concern subscale (e.g., "My community should try to address the needs of crossover youth"); personal ability to address the needs of crossover youth (e.g., "I can ensure that the needs of crossover youth are addressed effectively in my organization"), making up the Efficacy subscale; and the characteristics and worthiness of the 
task, making up the Complexity (e.g., "Addressing the needs of crossover youth is difficult to do.”), Compatibility (e.g., "Addressing the needs of crossover youth is consistent with the work I usually do.”), and Relative Advantage (e.g., "In general, addressing the needs of crossover youth is more effective in creating attitudes that support reintegration than our usual practices.”) subscales. The second section of the questionnaire is on Supporting Rights, and contains the same questions, altered to assess views regarding supporting the rights of crossover youth. All 42 items are rated on a 5-point Likert scale from 1 (Strongly Disagree) to 5 (Strongly Agree). Past research using this measure has found Cronbach's alphas between .72 and .85 for each subscale (Henderson et al., 2006).

\section{Procedure}

Mixed methods studies consolidate both qualitative and quantitative data to form a holistic representation of the phenomenon under study and are intended to take advantage of the strengths of each methodology while avoiding their limitations (Creswell, 2014). The present study employed convergent parallel mixed methods, utilizing a combination of the qualitative data from in-person interviews and the quantitative data from the two surveys. In this type of mixed methods design, the qualitative and quantitative data sources explore the same research questions and constructs and are collected at the same point in time (Creswell, 2014). Collecting both open- and close-ended data was intended to reduce bias, as interviewees may have felt pressured to provide positive responses when they were being audio-recorded.

Research Ethics Board approval was obtained in the summer of 2017. Qualitative and quantitative data were collected concurrently, in two waves, the first between December 2017 and April 2018 (Time 1), and the second, a follow-up, approximately nine months later between November 2018 and February 2019 (Time 2). To recruit participants, all members of the COYP 
steering committee were emailed a recruitment letter written by Dr. David Day, as the Principal Investigator of the evaluation and steering committee member (see Appendix F), as the committee contains members from most of the relevant stakeholder groups. If there was no reply to the initial email, a single follow-up email was sent. When a member replied expressing interest, an interview was arranged at the time and location of the participant's choice. After the appointment was set, participants were sent an email containing the interview guide and the consent form for their review. With the exception of two interviews at Time 1 and four at Time 2 , both the author and the post-doctoral research coordinator were present for all interviews.

Prior to the start of the interview, participants were given the opportunity to read over the consent form and ask questions. Participants then signed the consent form, which required a second signature to verify that the participant had agreed to audio recording of the interview (see Appendix G). One interviewee in the Time 1 interviews declined to be audio-recorded. Upon completion of the interview, participants were asked if they would be willing to pass the recruitment email onto other staff within their organization to expand data collection to more direct service providers who were not associated with the steering committee. Participants were then given the Stakeholder and Organizational Information Form, the Measure of Service Integration, and the Service Provider Adopter and Innovation Characteristics Questionnaire to complete. Nine interviewees at Time 1 and four interviewees at Time 2 asked to return the questionnaires at a later date due to lack of time.

Post-interview, audio recordings were transferred onto the secure lab drive on a laboratory computer and the recording was deleted from the recording device. Interviews were predominantly transcribed by three undergraduate-level research assistants, with several being completed by the author. As recommended by Braun and Clarke (2006), a randomly selected 10 
percent of interviews were checked against the transcripts for accuracy after the first round of interviews were fully transcribed. This check, completed by the first author and a post-doctoral level research coordinator, revealed significant discrepancies between the audio recordings and transcriptions, as well as difficulty interpreting esoteric terms and acronyms (e.g., OACAS). Thus, prior to analysis, the author listened to all audio recordings alongside the transcripts and corrected any errors. The post-doctoral level research coordinator was consulted for clarification around any terms that the author could not understand.

\section{Analysis}

In convergent parallel mixed methods, qualitative and quantitative data are analyzed separately, compared for convergence or discrepancy, and interpreted. Once analysed, the qualitative and quantitative data are merged using a side-by-side comparison approach, in which the qualitative results are presented first and the quantitative are compared to those results (Creswell, 2014). The first research question regarding the ability of the COYP to affect stakeholder collaboration was addressed using qualitative data from questions 6 and 7 in the interview. Similarly, the second research question regarding the ability of the COYP to affect stakeholder knowledge, skills, and attitudes was addressed using responses to questions 10 and 11 in the interview. The third research question, about the sustainability of such changes after the end of the Toronto pilot site, was answered using interview responses to the second interviews completed at Time 2, as well as comparing the quantitative data over time from the Measure of Service Integration and the Service Provider Adopter and Innovation Characteristics

Questionnaire. Responses to open-ended questions in the interview were also coded for themes relevant to these questions. 
Interview transcripts were analyzed qualitatively using data-driven thematic analysis. Thematic analysis is the close inspection of a data set to identify recurrent themes, a process that involves familiarization with the body of data, setting codes (i.e., features of interest), grouping of codes into overarching and meaningful themes, reviewing and refining selected themes, rereading the body of data to ensure appropriate and distinct themes have been selected and no data have been missed, naming of themes, and writing up an analysis consistent with the data (Braun $\&$ Clarke, 2006). The analysis was completed using an inductive and essentialist approach, and semantic themes, as described in Braun and Clarke's (2006) work. The Time 1 transcripts and audio-recordings were viewed independently by the author and the post-doctoral-level research coordinator, who then collaboratively decided on codes to be included in a coding scheme in a series of in-person meetings. Three interviews were coded together, with discussion of the relevant codes and additional codes that may be required. Similarly, the author and research coordinator met to discuss themes relevant to the second round of interviews. At this time, it was decided that the majority of the codes would be the same across time points, with additional codes for describing the impact of the COYP's removal from 311 Jarvis. The author then coded the remaining Time 1 and Time 2 interviews alone; however, the interpretation of the codes was completed with the input of the research coordinator. Given the nature of the codes as abstract, rather than dichotomously present or absent, no interrater reliability was calculated. The importance of reliability in qualitative research is equivocal (Armstrong, Gosling, Weinman, \& Marteau, 1997; MacPhail, Khoza, Abler, \& Ranganathan, 2016). NVivo version 12 Plus was used to facilitate analysis.

With respect to quantitative analysis, due to the small number of participants and even smaller number of completed questionnaires, quantitative data were interpreted visually and 
reported using descriptive statistics. Power analysis completed in RStudio using the "power" package indicates that for a paired samples t-test with a power of 0.8 , a sample including 15 pairs is required to detect even a large effect size (Cohen's $d=0.8$ ). This sample size did not exist for any of the possible comparisons. 


\section{Results}

\section{Qualitative Analysis}

Based on discussions between the author and the post-doctoral research coordinator, themes were identified pertaining to the three research questions centred around: 1) stakeholder collaboration; 2) stakeholder knowledge, skills, and attitudes; and 3) program sustainability. Though a variety of additional themes emerged in addition to those detailed below (e.g., voice of the youth), they will not be described here given the scope of the present research questions. Within each of these three areas, themes are organized into five sub-areas: 1) barriers for youth, which includes systemic or rights-interfering issues faced by crossover youth; 2) program implementation, as in activities completed by the COYP to achieve their desired outcomes; 3) barriers to program implementation, which included problems that slowed or prevented a complete implementation; 4) program outcomes, which included the results of the program activities; and 5) program recommendations, which included stakeholders' desired activities for future projects targeting crossover youth.

\section{Research Question \#1: Themes relevant to stakeholder collaboration.}

Barriers for youth. Several themes emerged indicating that stakeholders recognized the current systemic lack of collaboration, as reflected through a lack of continuous care and siloed systems, represented a barrier to crossover youth receiving the best care possible. In contrast, the stakeholders also recognized that there was careless information sharing by some service providers. These themes will be outlined below.

Siloed systems. Several interviewees expressed that the existing systems were cut off from one another and that there were few opportunities for services providers to collaborate. 
There were minimal attempts to connect service providers from different sectors serving the youth and to reconcile their different mandates.

10.1: I would just say that it was people kind of still stuck in their silo and not really understanding how to kind of branch out from that.

2.1: The youth's YJ counsel would never be invited. [...] Probation is never invited. [...] You might be seeing around a table of 10 people, and eight of them are from the Children's Aid Society.

Continuity of care. Another concern expressed by stakeholders was that youth experienced little to no continuity of care at the level of individual service providers. This discontinuity affected the ability of the stakeholders to work together efficiently and also affected the youth's experience, who dealt with a large cast of service providers to whom they had to explain their story.

1.1: There have been cases where, as you probably know, a lot of times whether it's the child and youth worker or the children's aid worker, sometimes they change like twice a year, three times a year and that's so horrible for these kids.

3.1: When it's piecemeal, is we have a court case in criminal law, then 3 months later, 2 months later they're at 47 Sheppard in front of a whole different judge with a whole different set of lawyers with a whole different agenda, rules, policies, practices, and outcomes and the disconnect is - I think that kids get caught in the disconnect.

6.1: Workers changing, so how do you keep up, keep everybody in the know, people kind of coming and going.

Confidentiality. Despite expressing views that collaboration needed to increase, stakeholders also expressed concern that sharing youths' information without caution could be problematic. They feared that careless information sharing could produce situations in which service providers spoke without the youth's consent, and without consideration of the impact on 
youth's care, particularly the outcomes of their criminal case. One specific example that several stakeholders provided was the inclusion of youth justice information in child welfare documentation that could eventually affect youth if they had children of their own before the age of 18. Similarly, a number of stakeholders expressed concern around the inappropriate sharing of Section 34 psychological assessment reports.

9.1: Historically, they were more linked and then there was a divide and that divide came because people thought that they were different proceedings and one shouldn't impact the other. Like the young person's family court proceedings really shouldn't have any impact on their youth criminal involvement and vice versa.

2.1: There is a laundry list of kind of individuals who may receive YJ information, but those individuals are then prohibited from further disclosing that information, and that's where I think the system breaks down.

Program implementation. Three main topics emerged with respect to activities implemented by the COYP at 311 Jarvis to increase collaboration.

Case conferencing. One of the most frequently referenced themes throughout all interviews was that of case conferencing, predominantly as organized by the COYP's case coordinator. Though case conferences theoretically could be organized at any time by other justice system players, stakeholders identified those organized by the case coordinator as more frequent and more productive. The coordinator invested their time in contacting serviceproviders relevant to the youth's care, arranging space and time for meetings, and generally streamlining the process. Documentation around confidentiality of meetings was shared and the meetings were attended by a diverse cast of stakeholders.

Interviewer: And this didn't exist before the COYP?

1.1: Well no, no. There were case conferences for sure but much more rare [...] I mean those things were always in the legislation but nobody did them, none, it was weird. 
10.1: Child welfare, defense, maybe the crown or like the bench, so like judge or justice of the peace, any mental health or outside resources, education. Just whoever is involved in the young person's life, could even be family or friends. Any culturally specific, so an elder, whoever the young person wants at the table.

12.1: Just [the case coordinator] having the resources and being able to identify the different players, like who is the CAS worker for this youth? What's her contact information? I mean [the coordinator] has resources that I don't know about and can't access, so that was very helpful.

13.1: I think it was that first case when we were meeting monthly for several months. Maybe 3 or 4 times.

Facilitating communication. Interviewed stakeholders also credited the project with increasing the flow of information between the systems and their respective service providers, at times through formal case conferences. This information included the views and wishes of the crossover youth.

10.1: Having conversations about what the young person wants, or what they need, or if they're AWOL, like how are we gonna - like things like that. It definitely helped with the communication piece.

11.1: All with proper consent, there can be a sharing of information or a giving of information, depending on the kind of consent you have, that enables for me the ability to have a much better understanding of what services are in place and to do some advocacy.

14.1: The exchanging of information with both parts - like the crown and duty counsel as well as keeping the young person's youth justice counsel up to date, as well as the group home staff.

Two-hatter counsel. Another effort to increase the integration of services for crossover youth included the training of two-hatter counsel and the referral of crossover youth to these lawyers. Two-hatter counsel were intended to take on both the youth justice and child welfare aspects of their legal case. Upwards of six two-hatter counsel were trained through the program 
to be competent in servicing youth for both their child welfare and youth justice proceedings.

Though most of the formal training was directed at counsel who were previously with the

Ontario Children's Lawyer, youth justice counsel were also trained.

11.1: The plan was to identify some youth criminal lawyers who wanted to become children's lawyers to do this kind of work, and another lawyer I knew, a children's lawyer...indicated interest from the children's lawyer child protection piece to being trained in the criminal piece.

13.1: [They] can actually explain things to the society because [they] have the youth criminal justice background. So the society actually didn't understand - because they don't do youth criminal work, so they didn't actually understand how to navigate through the youth criminal system.

Barriers to implementation. Though the interviewed stakeholders viewed the project's efforts to increase collaboration as successfully implemented, they identified a number of barriers that slowed or decreased the impact of these activities.

Buy-in. Despite the participating stakeholders' confidence in the COYP's importance, they reported that other stakeholders were not equally as supportive or involved in the program as they were. Buy-in varied from individual to individual, but in particular, interviewees focused on youth's defense counsel (without whom services could not be offered to youth) who, as a group, were frequently unwilling to cooperate. Some interviewees also suggested that the project's educational efforts were primarily reaching those who had already bought-in to the program's philosophy.

1.1: There's some people, and I'm going to say a lot of defense lawyers and frankly I think some duty counsel too that just don't really get it.

10.1: There are people at the table that you know were part of the problem. And had those philosophies and that kind of culture embedded in them. 
13.1: For lawyers that aren't interested, then that the young person isn't going to get the voice. Their voice is through their lawyer, so it is very lawyer dependent.

Lack of time and resources. Participating stakeholders recognized that those servicing crossover youth are constantly under-resourced, and this prevented them from engaging with the project's philosophy and participating in activities, like case conferencing.

10.1: CAS workers are--they're all overworked.

13.1: Funding is an issue. So I can say lawyers aren't interested, but it could also be that lawyers like "I can't show up to 5 things and not get paid for them."

14.1: Well, there is only one of me, and sometimes there's 20 of them.

Professional hierarchies and philosophies. Linked to the issues of buy-in, some stakeholders identified opposing philosophies within different fields as a barrier to working collaboratively together. Examples given included CAS workers prioritizing the safety of the youth at all times at the cost of the youth's autonomy, and defense lawyers prioritizing youth confidentiality and privacy over information sharing.

1.1: A lot of those people really don't normally do youth work and that's really old school, like really old school. Like I'm not talking to you, you better go away, no this is private.

18.1: You get somebody who has done it for a long time, their instinct, their gut, tells them to do it one way, it's so difficult to have someone to unlearn that, even if it is the exact opposite of what they should be doing. They look at themselves as having a successful career and doing successful work

19.1: They didn't want to disclose anything about their client, they only wanted to try and learn from the other side, but never to play equal and to share. So, by nature, you can understand the social worker from the children's aid, when being asked questions by defense counsel when the defense counsel's sharing nothing, but only wants information to flow one way they're resistant. 
Program outcomes: Collaboration. Despite the above-noted barriers, the interviewed stakeholders described a multitude of opportunities that they had to collaborate with each other and with the staff in the program. Specifically, case conferences were identified as an excellent context in which to share information and develop collaborative plans involving multiple stakeholders.

1.1: You got how many brains at a table and to say oh well we can do this, we can do that, we can do this. Or, you know, pointing them to the mental health court worker, pointing them to other different organizations that can help. Maybe some things that weren't always on the radar. So I think, you know, obviously the more people the more brain storming can happen.

14.1: You would gather whoever was involved together and you have a little scrum as to what you hope will happen, what the plan is, and whether there's a role for the mental health worker to chip in, and what other information might we need and who can help get it. So they would be a part of that as well.

18.1: When everyone was coordinated properly, there wasn't duplication, there wasn't having the kid do the same thing in different spheres, and them not knowing about it. And, I think you had more...maybe there was more deliberate plan, like they are going to do this first and then this.

8.1: Overall, I do think that there is a lot more collaboration, just people coming together to case conferences and more discussions between the project and lawyers and things like that, so things are moving forward.

\section{Program recommendations.}

Full-time case coordinator. The need for a full-time case conference coordinator was mentioned in 15 out of 30 interviews, during seven of which stakeholders suggested that one should be employed at every courthouse in Ontario due to the involvement of crossover youth in multiple jurisdictions. Interviewees viewed the case coordinator as fulfilling a unique role of 
facilitating communication and collaboration in the courthouse that was not appropriate for other service-providers to take on.

1.1: Well absolutely we definitely need somebody to be on every site.

3.1: In terms of knowledge and sharing knowledge - there are rules against it. So it wouldn't be appropriate for somebody, individually, to start running around and calling people, that's an issue. So there has to be a worker in every courthouse.

12.1: Keep [the case coordinator] here. Don't let [them] go!

Systematic assignment to two-hatter counsel. Stakeholders identified the referral process to two-hatter counsel as either inconsistent or non-existent. The majority of crossover youth had active youth justice and child welfare proceedings at different times, resulting in them obtaining a non-two-hatter lawyer depending on the system first activated. Participants recommended a thorough investigation into how existing criminal counsel are obtained, and the creation and maintenance of a list of two-hatter lawyers by Legal Aid to whom crossover youth may be referred.

11.1: One of the reasons it's very important to be able to identify these cases early so we can get the two-hatters involved because of course once the youth has a criminal lawyer, typically the lawyer would not be inclined to give up the case to someone else just because they're not a two-hatter, right?

21.2: If the court maintained a list - if - if legal aid maintained a list of two-hatters lawyers so that when a kid hits the system from the criminal side, if somebody like [the case coordinator] is there who can identify them and then go to that list... 


\section{Research Question \#2: Themes relevant to stakeholder knowledge, skills, and attitudes.}

\section{Barriers for youth.}

Stigma. Participating stakeholders identified that crossover youth face a lot of stigma. This stigma often emerged subtly in the attributions other service providers made about the youth's behaviour. Participants lamented that some service providers viewed the youth as the problem, rather than the system in which they were operating and their history of trauma.

10.1: Often in child welfare and specifically with the criminal pieces, they're blamed, it's like "you're the problem."

17.1: I've heard CAS workers say well you know maybe he just has to spend some time in custody. Which is just sort of antithetical to the whole sort of project of crossover youth but then although youth criminal justice system as a whole.

9.1: Some of the barriers that I often face with young people who are involved in child welfare is just the workers' perspective on the young people, and it really being the young person's fault.

Difficulty engaging. Participants also expressed that crossover youth were a particularly challenging population to serve because of youth's difficulty engaging due to a lack of material resources (e.g., lack of cell phone, transportation) and assumed lack of interest. At times, arranging meetings would be difficult. This would in turn bias service providers against the youth when they did not understand the youth's context.

10.1: Then they don't show up, for whatever reason right? Hard to get a hold of, cellphones in and out of service, or they don't have access to cell phones.

11.1: I mean these are youth, right? They have difficulty getting to the lawyer's office, they may miss the meeting. They might disappear and not be in touch.

12.2: They're a very hard group of people to provide services to because they've had so much experience with people trying to help them and impose help on them and 
counselling them that by the time we get them they're pretty jaded and reluctant to engage.

\section{Program implementation.}

Case coordinator as a resource. Participating stakeholders were emphatic that the case coordinator had been a resource in educating them about crossover issues, the philosophies of the COYP (e.g., youth-centering), and potentially helpful resources. The case coordinator was utilized as a specialized consultant by a variety of service providers.

1.1: Just being a resource, someone to call, to say I'm really stuck what do I do? Do you have an idea? And usually [the case coordinator] has ideas, right?

12.1: I mean, even when [they're] not in the building I could call [them]. If I have a question say "what about this? When can you be here [...]?" and just a general reference if I have some questions about CAS in particular and the project.

14.1: As well as it was nice to have someone accompanying me and sharing their thoughts and opinions around what my work was and what it wasn't, because if you work in isolation for a long time, it can be nice to have other people's perspective.

Education. Stakeholders reported attending a number of educational events held by the COYP staff that they found important to their own learning and attitudes. Activities within the city of Toronto included community-wide presentations involving former crossover youth, educational events led by stakeholders in their respective fields, information sharing through listservs, Career Professional Development events, and, most recently, a community symposium on the project.

6.1: We did round tables with youth who shared scenarios and talked about, "here was my experience" and the group kind of had to problem solve the experience of the youth. 
1.1: At the beginning of the project there were seminars, I mean there was like one where it lasted from like about one in the afternoon to almost nine at night at the children's aid office.

Trauma-informed approach. In addition to the aforementioned educational events, stakeholders identified training specifically around applying a trauma-informed lens to the care of crossover youth. Participants expressed their knowledge explicitly, through discussion of the definitions and importance of trauma-informed care, but also reflected it in their explanations of crossover youths' behaviour.

3.1: They are responding inappropriately, but responding to their trauma, and so we need to help them figure out how to manage all that trauma, because we can't take it away.

11.1: He is already the victim of neglect or abuse, he is already facing these traumas, we really need to think about what the impact is going to be on him if he were for example to stay in a longer term in a locked facility, that type of thing, because he is vulnerable, right?

\section{Barriers to implementation.}

What is COYP. Despite the project's efforts at cross-sectoral education, some stakeholders indicated they had difficulty understanding the purpose and goals of the COYP, and whether it was still operational. It also became apparent during two interviews that the interviewees had difficulty understanding the term crossover youth and who would be considered a part of that population.

1.1: I can talk it up, and I do talk it up, with peers whatever people want to know about it. But some people have never heard of it still, even though they're kind of in this world.

14.1: Youth justice lawyers are saying “what about crossover?” and I'm kind of going "it's not taking place anymore", and they are going like "yes it is" so it has created a bit of confusion that it is no longer available in this jurisdiction. 
4.1: I'm not sure that many people even know what it is.

Length of the program. Several stakeholders complained that the short duration of the program reduced the effectiveness of its implementation. According to one interviewee, the project ended just as it was gaining a positive reputation.

8.1: Another thing is just longevity; the longer the project is here, the greater the reputation it will have, the more referrals it will get and the more trust in the process.

13.1: Now people that have crossover youth in other court houses are saying "oh, I hear about this project, what does this mean for my kid?" I say well actually the project is you missed the boat!

\section{Program outcomes.}

Sensitization/Culture shift. One of the most common themes throughout the interviews reflected stakeholders' belief that service providers in general were becoming more aware of the systemic issues faced by crossover youth (e.g., bail conditions, placements). As a result of this greater awareness, those issues were kept in mind during service provision. This general shift in attitudes was viewed as extending past Toronto. Some stakeholders provided the caveat that the changes were not fully borne out of the COYP, rather that the COYP itself was a part of a larger shift towards a trauma-informed, less criminalizing view of justice-involved youth.

9.1: I think the presence of the cross over project has brought just more awareness to the court of these young people who are in both systems and trying to see how involvement in both systems can be really complicated for young people.

4.1: It has opened the door for people to think differently.

3.1: I think that once we identify somebody who is crossover, it turns everybody's mind to the issues that impact crossover youth specifically. So that has been one of the key components is that awareness of criminal judicial actors and what that means to be child welfare-involved. 
Personal knowledge, skills, and attitudes. Largely, stakeholders expressed that the project had increased their own knowledge of crossover issues, skills in working with crossover youth, and their attitudes towards crossover youth. Knowledge and attitudes were linked to empathy built through gaining a greater understanding of crossover youth's lives. Some stakeholders also expressed a greater understanding of other stakeholders' roles. Many cited gaining skills in the area of advocacy, and that the program had given them the ability to pursue better criminal justice outcomes for their clients, such as less restrictive bail conditions.

1.1: I think I gained a more--a deeper understanding of how to interact and how to appreciate young people who've gone through serious, serious trauma.

10.1: I've learned a lot, you know, and it was again like I attribute that to [...] my work with the youth, seeing what the real issues are and it being very clear to be like as kind of like a reality check for me.

13.1: You can see it, you can just see the struggles.

9.1: Being an advocate and being an ally can be similar, but they're also different, and I think, I wanna, I hope that I'm developing skills to be both for the young people. I think being part of the crossover project, being involved in it, has helped me to build on that.

Recommendations: Education. Despite progress on the whole, stakeholders still believed further and ongoing education was required to better serve crossover youth. In particular, they mentioned a need to market the project and its goals to enhance buy-in from groups who continued to have attitudes contrary to the project. Interviewees specifically referenced defense counsel and Children's Aid workers as groups to be targeted. Though there had been some uptake from those groups, it was inconsistent. 
9.1: Clarification around like what... what are you... what are you looking to do and what are you hoping to achieve.

6.1: Something around the whole stakeholder engagement - how do we get all of those groups understanding better that are having to serve these youth? It seemed like there were really key champions, which is important, but how do we get everybody who is working with these youth to understand it?

4.1: There needs to be a much better marketing of the concept of crossover youth.

\section{Research Question \#3: Themes relevant to sustainability.}

At the end of 2017, the case coordinator was phased out of 311 Jarvis as the pilot had ended. As such, in the Time 2 follow-up interviews beginning November 2018, participating stakeholders were asked explicitly which pieces had been maintained and which pieces had not. The following themes emerged: loss of case coordinator; loss of case conferencing; maintained knowledge, skills, and attitudes; and possible sustainability planning.

Loss of case coordinator. Participants felt that the removal of the case coordinator was a major loss for them and meant a major loss for their crossover clients. The case coordinator again was described as having a unique role within the courthouse that was not easily filled by other service providers.

18.2: I think there was a lot of day-to-day logistical things um time-consuming work that a, that a case conference facilitator did - relational work that they did, that just doesn't fall within the purview of other stakeholders.

2.2: We've lost some of that ability to facilitate this integration by not having a formalized structure actually at the court who can facilitate that.

17.2: Without the case coordinator role, there's a risk of losing that really strong case management, or case coordination function, because who does that fall to if there's not a dedicated person there, who's trying to get everybody in a room. 
Loss of case conferencing. Participants largely felt that the loss of the case coordinator had resulted in a substantial reduction in the overall number of case conferences, which they felt were critical to coordinated care.

8.2: Without a case conference coordinator I haven't seen a lot of case conferencing going on.

5.2: Well the case conferences aren't happening, so that has not been sustained.

3.2: The effectiveness has been reduced dramatically, I don't think there's been one case conference since [the case coordinator] left. Maybe there's been one, I don't want to misspeak. There's been very few.

21.2: I know it was getting much more, much more difficult to try and get case conferences organized without [the case coordinator] to participate in the process. So I worry that other youth may have lost that opportunity, because [they] would just get everybody into a room at the same time. And that's not always something that criminal counsel could achieve.

Maintained knowledge, skills, and attitudes. The main "product" of the COYP that participants felt was maintained was the skills and knowledge that they and other stakeholders had gained through interaction with the project. Stakeholders who participated in the larger steering committee for the project also felt that their learning was ongoing.

22.2: I mean I know terminology now thanks to the subcommittee that I spoke to and individual lawyers [...] I mean I understand concepts now, and processes that I didn't before.

3.2: But certainly people's practices have changed. So, you know, our--everybody is in tune to finding out what is your background and if you're COY or not.

5.2: I think there's some things that people have learned from that experience that they've been able to now continue using since there isn't a case coordinator in court anymore. So that they're still able to use some of those principles. 
8.2: I've found like shifting your philosophy has really helped and I think crossover has done a really good job of emphasizing that. That's definitely one of the lessons I've learned. And that's helped me out a lot actually in the work that I do.

Possible sustainability planning. Several participants mentioned efforts by the program to have someone acting in the case coordinator role. There was some discussion of students from the Child and Youth Care program at Ryerson University assisting in the 311 Jarvis courthouse, with limited scope. There was also discussion of the addition of a case coordinator position alongside that of the mental health court workers.

1.2: The whole idea is to have Turning Point get funding enough so that we have a full time case conference coordinator sitting at 311 and [co-developer] said in the interim she would hand pick two MSW students to do a placement.

\section{Quantitative Analysis}

\section{Stakeholder collaboration.}

Cronbach's alpha. Cronbach's alpha was calculated for each Measure of Service Integration subscale to decide which scales were interpretable (see Table 3). Most scales had acceptable reliability, including meeting needs, supporting rights, child welfare, health, and youth justice. However, at Time 2, the Addictions scale had an alpha of 0.66 , the Children's Mental Health scale had items with 0 variance, and the scores on Housing/Shelter violated assumptions of the test. At both time points, there were too few cases to calculate Cronbach's alpha for the Other subscale. 
Table 3

Measure of Service Integration - Subscale Means and Cronbach's Alphas Across Time Points

\begin{tabular}{|c|c|c|c|c|c|c|c|}
\hline $\begin{array}{l}\text { Scale } \\
\text { Subscale }\end{array}$ & $\begin{array}{l}\text { No. } \\
\text { Items }\end{array}$ & $\begin{array}{c}n \\
(\mathrm{~T} 1)\end{array}$ & $\begin{array}{l}\text { Cronbach's } \alpha \\
\text { (T1) }\end{array}$ & $\begin{array}{l}M(\mathrm{SD}) \\
\quad(\mathrm{T} 1)\end{array}$ & $\begin{array}{c}\text { Cronbach's } \alpha \\
\text { (T2) }\end{array}$ & $\begin{array}{c}n \\
(T 2)\end{array}$ & $\begin{array}{l}M(\mathrm{SD}) \\
\quad(\mathrm{T} 2)\end{array}$ \\
\hline \multicolumn{8}{|c|}{ Measure of Service Integration } \\
\hline Meeting Needs & 6 & 11 & 0.90 & $5.65(0.92)$ & 0.82 & 11 & $5.58(0.84)$ \\
\hline Supporting Rights & 6 & 8 & 0.85 & $5.79(0.70)$ & 0.82 & 11 & $5.59(0.90)$ \\
\hline Addictions & 5 & 10 & 0.90 & $3.84(1.64)$ & 0.66 & 9 & $4.18(1.83)$ \\
\hline Child Welfare & 5 & 10 & 0.79 & $5.00(1.56)$ & 0.77 & 10 & $5.14(1.28)$ \\
\hline Children's Mental Health & 5 & 8 & 0.92 & $4.87(1.83)$ & + & 10 & $5.14(1.50)$ \\
\hline Health & 5 & 9 & 0.90 & $3.89(2.02)$ & 0.72 & 10 & $3.30(1.81)$ \\
\hline Housing/Shelter & 5 & 9 & 0.84 & $3.93(1.65)$ & - & 10 & $4.03(1.62)$ \\
\hline Youth Justice & 5 & 10 & 0.93 & $5.40(1.81)$ & 0.83 & 10 & $5.2(1.73)$ \\
\hline Other & 5 & 4 & ++ & $3.25(2.87)$ & ++ & 2 & $4.00(4.24)$ \\
\hline
\end{tabular}

Note. All items rated on scale from 1 (Strongly Disagree) to 7 (Strongly Agree) and averaged for a total scale score.

T1- Time 1; T2 - Time 2; + scale has 0 variance item(s); - assumptions for data violated; ++ too few cases to calculate 
Descriptives. Though no statistical testing was completed due to the limited number of participants who completed the scales ( $n \approx 11$ at both time points), results from the Measure of Service Integration suggest that stakeholders' level of integration with other services remained largely the same from Time 1 to Time 2 (see Figure 1 and Table 3). Of note, the responses on the mental health scale may be an underestimate due to a missing number on the scale (i.e., all mental health items were missing the number 7). Some stakeholders drew in their own seven and circled it, while others considered the six the ceiling. Thus, results from the scale should be interpreted with caution.

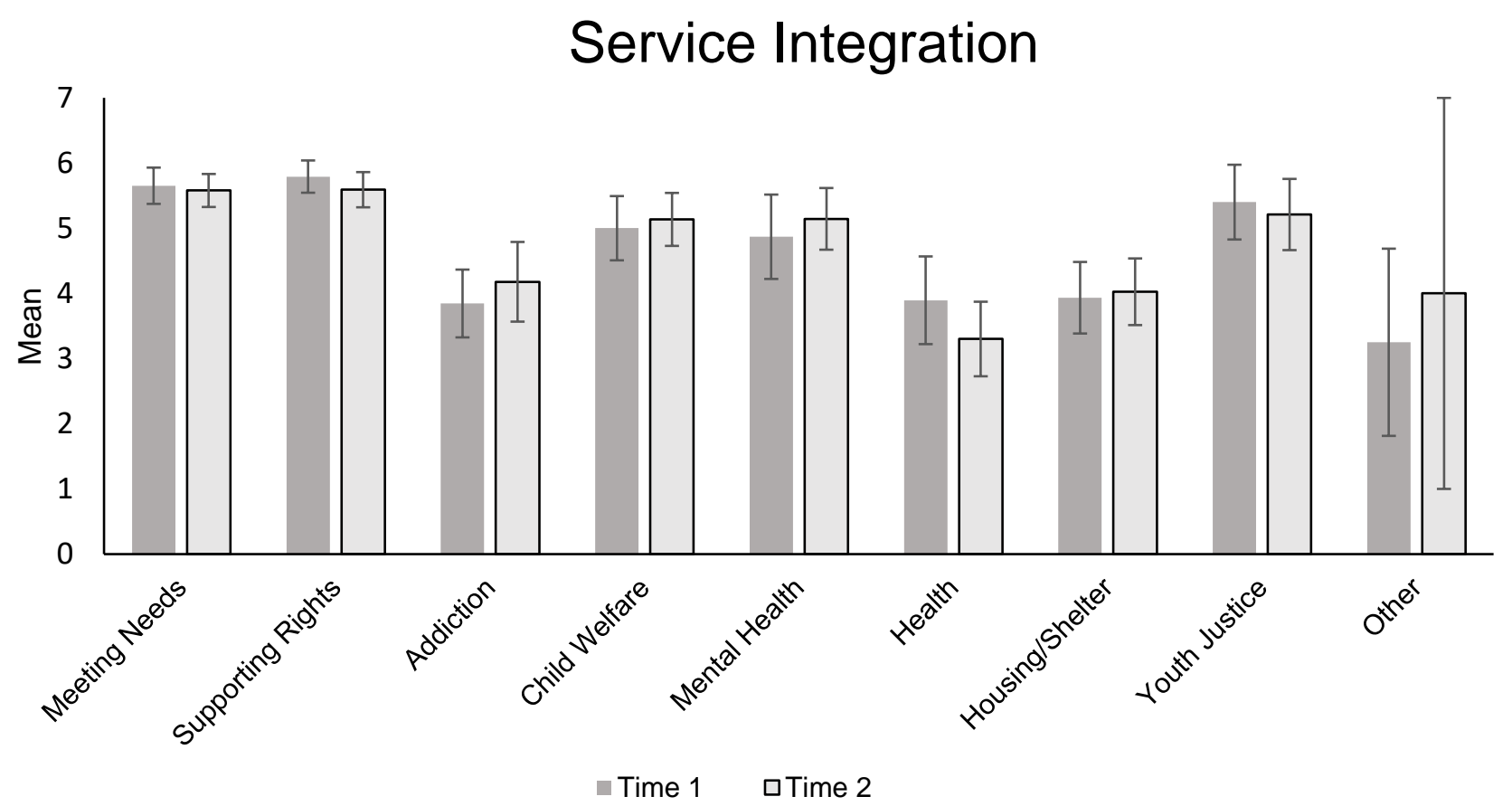

Figure 1. Mean service integration across two time points. Bars represent standard error. 


\section{Stakeholder and innovation characteristics.}

Cronbach's alpha. Cronbach's alpha was calculated for all subscales of the Service Provider Adopter and Innovation Characteristics Questionnaire (see Table 4).

Cronbach's alpha could not be calculated for the Concern subscale at either time point because of the number of items with zero variance. Visual examination of the data showed that for the majority of stakeholders, all items were rated to indicate the maximum concern. Specifically, Item 1 ("I believe addressing the needs of crossover youth is very important.") and the reverse scored Item 4 ("I don't know why the needs of crossover youth are important for my agency to address.”) were rated 5 and 1 respectively by all participants.

Similarly, the compatibility scale had a problematically low alpha at Time 1 for both Meeting Needs and Supporting Rights and was incalculable because of items with no variance at Time 2. Visual examination of the individual data for the meeting needs Compatibility subscale at Time 1 suggests that at least one person - likely mistakenly - missed the reverse-scored item (“Addressing the needs of crossover youth does not reflect my personal values.") when they selected all fives in their response, while all other responders rated each item as a four or five. This low variance in items combined with a mistaken response likely produced the low alpha.

At Time 1 for Supporting Rights, the fourth compatibility item was rated as 5 by all except the same participant who again appeared to miss the reverse coded item. Indeed, if the fourth item was removed, Cronbach's alpha increased to 0.83 . At Time 2 for the same subscale, all participants rated every item as indicated maximum compatibility, with the exception of one participant who selected four out of five for the first three items. 
Table 4

Reliability Coefficients for all Stakeholder and Innovation Characteristics Subscales.

\begin{tabular}{lccc}
$\begin{array}{l}\text { Scale } \\
\text { Subscale }\end{array}$ & $\begin{array}{c}\text { No. } \\
\text { Items }\end{array}$ & $\begin{array}{c}\text { Cronbach's } \boldsymbol{\alpha} \\
\text { (Time 1) }\end{array}$ & $\begin{array}{c}\text { Cronbach' } \\
\text { (Time }\end{array}$ \\
\hline $\begin{array}{l}\text { Stakeholder and Innovation } \\
\text { Characteristics - Addressing Needs }\end{array}$ & & & \\
& & & \\
Concern & 4 & + & + \\
Self-Efficacy & 4 & 0.84 & 0.65 \\
Complexity & 5 & 0.74 & 0.69 \\
Compatibility & 4 & 0.32 & 0.72 \\
Relative Advantage & 4 & 0.91 & 0.86
\end{tabular}

\section{Stakeholder and Innovation}

Characteristics - Supporting Rights

$\begin{array}{llcc}\text { Concern } & 4 & + & + \\ \text { Self-Efficacy } & 4 & 0.92 & 0.74 \\ \text { Complexity } & 5 & 0.70 & 0.71 \\ \text { Compatibility } & 4 & 0.02 & + \\ \text { Relative Advantage } & 4 & 0.88 & 0.91\end{array}$

Note. + Scale has 0 variance item(s).

Descriptives. Stakeholders' characteristics and attitudes towards meeting crossover youth's needs and supporting their rights remained likewise unchanged from Time 1 to Time 2, with the exception of the complexity scale for supporting rights (see Figure 2, Figure 3, and Table 5). Visual examination of the Complexity scale suggested a decrease somewhat from Time 1 to Time 2 (i.e., the error bars do not overlap), so a paired samples t-test was completed using the data from the five Time 1 participants $(M=3.44, S D=0.56)$ who were maintained at Time 2 $(M=2.3, S D=0.62)$, despite being underpowered. The scores changed significantly from Time 1 to Time $2, t(5)=4.45, p=.011$. Concern and compatibility were close to the ceiling of 5 for both meeting needs and supporting rights. 


\section{Stakeholder and Innovation Characteristics \\ Meeting Needs}

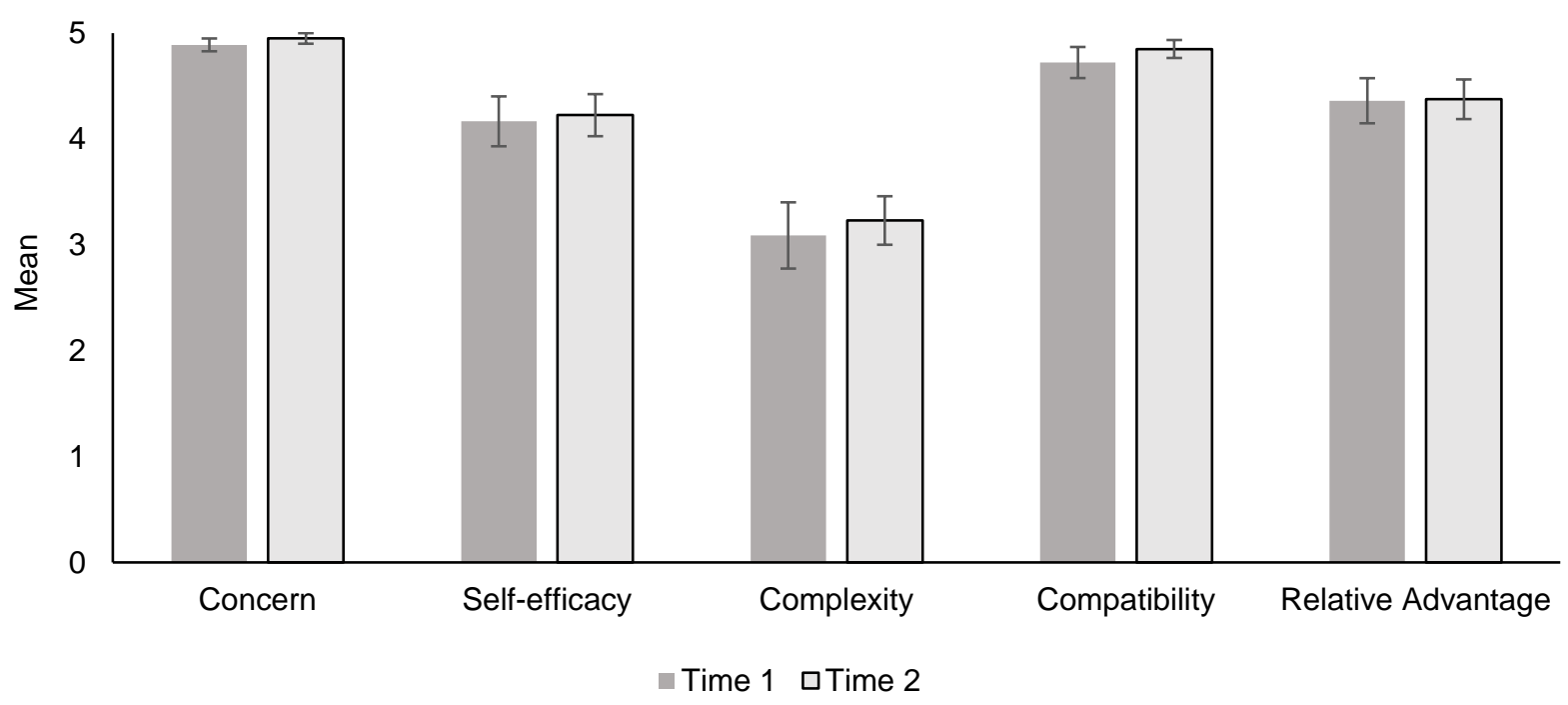

Figure 2. Mean stakeholder and innovation characteristics regarding meeting needs across two time points. Individual scores were responses to questions about their concern and self-efficacy in meeting crossover youth's needs, as well as their assessments of the complexity, compatibility and relative advantage over current practices in meeting crossover youth's needs. Bars represent standard error.

\section{Stakeholder and Innovation Characteristics \\ Supporting Rights}

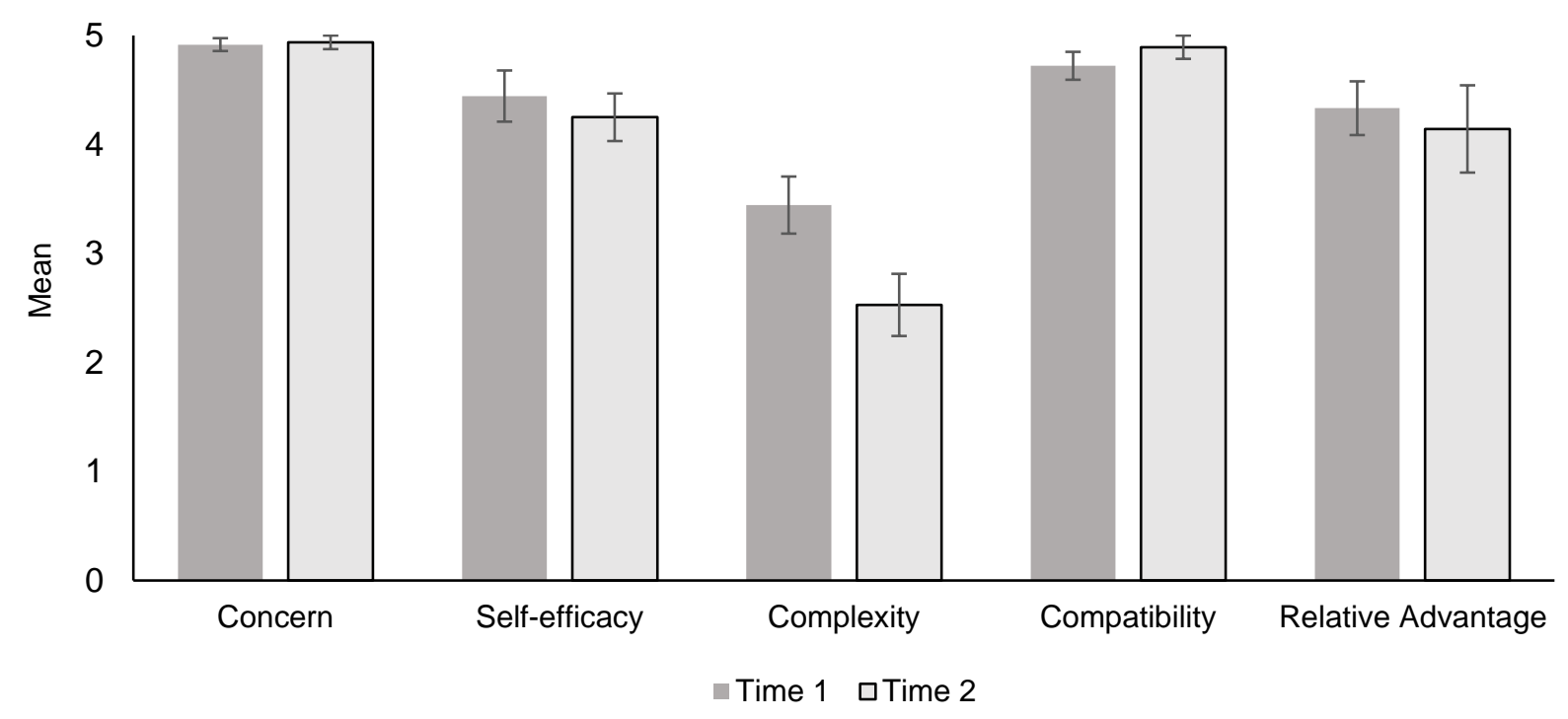

Figure 3. Mean stakeholder and innovation characteristics regarding supporting rights across two time points. Individual scores were responses to questions about supporting the rights of crossover youth, including the importance of the task, their efficacy in doing it, the complexity of the task, the compatibility with their current mandate, and the advantage over current practices. Bars represent standard error. 
Table 5

Mean Scores for Stakeholder and Innovation Characteristics

\begin{tabular}{lcccc}
$\begin{array}{l}\text { Scale } \\
\text { Subscale }\end{array}$ & $\begin{array}{c}\boldsymbol{n} \\
\text { Time 1 }\end{array}$ & $\begin{array}{c}\boldsymbol{M}(\mathbf{S D}) \\
\text { Time 1 }\end{array}$ & $\begin{array}{c}\boldsymbol{n} \\
\text { Time 2 }\end{array}$ & $\begin{array}{c}\boldsymbol{M}(\mathbf{S D}) \\
\text { Time 2 }\end{array}$ \\
\hline $\begin{array}{l}\text { Stakeholder and Innovation } \\
\text { Characteristics - Meeting Needs }\end{array}$ & & & & \\
& & & & \\
Concern & 9 & $4.89(0.18)$ & 10 & $4.95(0.16)$ \\
Self-Efficacy & 9 & $4.17(0.71)$ & 10 & $4.23(0.63)$ \\
Complexity & 9 & $3.09(0.94)$ & 10 & $3.23(0.72)$ \\
Compatibility & 9 & $4.72(0.44)$ & 10 & $4.85(0.27)$ \\
Relative Advantage & 9 & $4.36(0.63)$ & 10 & $4.38(0.59)$
\end{tabular}

Stakeholder and Innovation

Characteristics - Supporting Rights

$\begin{array}{lllll}\text { Concern } & 9 & 4.92(0.18) & 8 & 4.94(0.18) \\ \text { Self-Efficacy } & 9 & 4.44(0.70) & 7 & 4.25(0.58) \\ \text { Complexity } & 9 & 3.44(0.79) & 7 & 2.53(0.75) \\ \text { Compatibility } & 9 & 4.72(0.38) & 7 & 4.89(0.28) \\ \text { Relative Advantage } & 9 & 4.33(0.74) & 7 & 4.14(1.06)\end{array}$

Note. All items rated on scale from 1 (Strongly Disagree) to 5 (Strongly Agree) and averaged for a total scale score.

\section{Discussion}

The present study examined the effect of a program for crossover youth on stakeholders' self-reported collaboration, knowledge, skills and attitudes, as well as the sustainability of those changes in the absence of designated staff at a courthouse in Toronto, Ontario. Overall, stakeholders were able to identify barriers for youth, activities implemented by the project, barriers that got in the way of implementation, outcomes of the project, and recommendations for the future in each of those areas. The following sections summarize the qualitative and quantitative findings in reference to each research question under investigation and integrate 
those findings with those of studies examining other programming for crossover youth (i.e., Project Confirm and the CYPM).

\section{Research Question \#1: How did the COYP affect stakeholder collaboration?}

Overall, the COYP's activities were consistent with the goals relevant to collaboration that were identified in consultation with stakeholders (Scully \& Finlay, 2015): the project was successful in promoting greater collaboration between child welfare and youth justice actors.

Stakeholders readily identified that stakeholder collaboration had the potential to improve care for crossover youth, as in past research (e.g., Bala et al., 2015; Scully \& Finlay, 2015), but that there were a number of barriers to it. The systems in which stakeholders operated were described as "siloed" with little to connect them. This separation was a factor in the discontinuous care experience by crossover youth, which was exacerbated by the frequent staff turnover at many agencies. This turnover is reflected in our own data collection, wherein four stakeholders left roles between Time 1 and Time 2. This observed lack of coordination was largely mirrored in past research on crossover youth, such as in Bala and colleagues (2015). Stakeholders also expressed concern that collaboration without consideration of potential violations to youth's confidentiality could produce negative consequences for the youth, which was not previously addressed in past research. Indeed, both Project Confirm (Conger \& Ross, 2001) and the CYPM (Stewart et al., 2010) required the open exchange of information between child welfare and youth justice for the sake of identifying crossover youth.

The project successfully employed a designated court worker (i.e., the case coordinator) to facilitate information exchange and case conferencing, who was greatly appreciated as a resource by service providers within and outside the courthouse. This is consistent with the findings of Project Confirm (Conger \& Ross, 2001), wherein the use of designated court staff to 
connect siloed systems through conferencing was successful. The COYP also successfully educated and utilized two-hatter lawyers who were able to operate in both the youth's child welfare and youth justice proceedings, overall integrating the legal aspect of those crossover youth's care. Importantly, according to the quantitative data, the greatest amount of reported collaboration appeared to be in the areas of child welfare, mental health, and youth justice, compared to addictions, health, and housing/shelter, which is consistent with the project's goal to target collaboration between child welfare and youth justice. However, these implementation efforts were hampered by a lack of buy-in, resources, and differences in professional philosophies.

In order to further enhance collaboration, stakeholders recommended the employment of a full-time case coordinator at every courthouse in Ontario, as well as the development of a functional referral process to two-hatter counsel.

\section{Research Question \#2: How did the COYP affect stakeholder knowledge, skills, and attitudes towards crossover youth?}

Generally, stakeholders reported that their participation in the project had increased their knowledge and skills in working with crossover youth through cross-sectoral education and training, as intended (Cross-Over Youth Project, 2016). Additionally, stakeholders reported that there was an overall culture shift in their respective fields to a philosophy that was shared with the crossover project. Similar language was used by stakeholders who experienced change as a result of the implementation of the CYPM in their county (Haight et al., 2014). Additionally, as intended (Cross-Over Youth Project, 2016), the case coordinator acted as a resource for other service providers. Stakeholders also reported attitude change through exposure to the youth. 
Stakeholders' identified barriers suggest that they view crossover youth as a population that is at times difficult to engage with, consistent with empirical research on the population (e.g., Halemba et al., 2004). Their responses were also consistent with past research finding that crossover youth are a population that is likely to be stigmatized (Bala et al., 2015; Chapin \& Griffin, 2005) which may affect service providers' attitudes toward them (Conger \& Ross, 2001; Tam et al., 2016; Ryan et al., 2007). However, the sample of stakeholders that was interviewed in the current study responded on the questionnaires in ways that suggest they, even at Time 1, felt strongly about crossover issues, as their self-rated concern was near the ceiling for both addressing the needs and supporting the rights of crossover youth.

In order to enhance skills, knowledge, and attitudes, the project marketed the cause through listservs, organized a number of cross-sectoral learning opportunities for stakeholders, and attempted specialized training for certain service sectors. In particular, stakeholders identified a trauma-informed approach as central to the teachings of the project. Though it was not directly their role, the case coordinator was also a resource that stakeholders cited in their learning.

Despite stakeholders' general assertion that they had gained knowledge from the project, the responses of those who had difficulty understanding the scope of the project as well as difficulty understanding who belonged to the population of "crossover youth" suggest that these concepts are hard for people to understand when they are not repeatedly exposed to the information. This finding fits neatly with those of Haight et al.'s (2014) interviews with stakeholders about their experience with the CYPM, a program with similar aims and broad goals. Both sets of stakeholders found it difficult to understand the projects that were targeting many aspects of the youth's care. Also, in general, the definitions of crossover are vague and 
there are multiple routes to becoming a crossover youth (Herz, Ryan, \& Bilchik, 2010) and this can make it hard to communicate with stakeholders how to identify the youth and provide services. Stakeholders also suggested that the length of the project was too short for the desired breadth of learning. As in past research (Gallegos \& Roller White, 2007), the stakeholders called for additional marketing of the project and ongoing education.

\section{Research Question \#3: Were the changes in stakeholder collaboration, and stakeholder skills, knowledge, and attitudes sustained in the year following the end of the pilot?}

Overall, stakeholders felt that their own and other stakeholders' additional knowledge, skills, and changes in attitude had been maintained at the Time 2 interviews. Largely, the quantitative data supported this theme, in that visual examination of the data suggest no clinically significant change in stakeholders' concern about meeting the needs of crossover youth and supporting the rights of the youth, as well as their perceived efficacy to do so.

However, stakeholders also felt that their ability to coordinate with other service providers to assemble for case conferences had been negatively impacted by the loss of the case coordinator. Despite this loss, the quantitative data indicated little to no change in degree of collaboration between stakeholders at the closure of the project and approximately nine months later; stakeholders rated their integration in meeting the needs and supporting rights of crossover youth as approximately the same. Similarly, their collaboration with the service providers in the addictions, child welfare, mental health, health, housing/shelter and youth justice sectors was largely unaffected over time. Overall, the combination of the qualitative and quantitative data suggests that while collaboration was still occurring at the same frequency and intensity at the end of the project and nine months later, stakeholders were interpreting it as less successful. 


\section{Significance of Findings for Future Intervention}

Given the intersection of multiple systems and their high service usage, attempting to improve the quality of care for crossover youth is a complex and resource-intensive endeavour. The Toronto site of the COYP, the first of four sites to receive funding, aimed to alleviate the systemic barriers faced by youth by increasing the collaboration among service providers, and educating them to enhance their knowledge and skills, as well as altering their attitudes, in addition to a variety of other activities. Our results suggest that stakeholders found the project to be successful in these endeavors, and that they overall felt the project changed their own and others' practices.

Though it is generally agreed upon that inter-sectoral collaboration is an important goal when helping crossover youth, what that collaboration actually looks like in practice and how to increase it can be difficult to operationalize (Horwath \& Morrison, 2007). The present study illustrated that the employment of a case coordinator was received very positively by stakeholders, and that the role brought typically siloed stakeholders together for information sharing, predominantly in the context of case conferences. Of note, despite stakeholders' recognition of the benefit of organizing conferences, stakeholders felt it did not fall within their mandate or within the mandate of other stakeholders operating in the youth courthouse, and thus the presence of a case coordinator was necessary. When the case coordinator was removed, there was drift back to practice-as-usual with respect to case conferencing. Future projects targeting crossover youth should recognize that case coordinators are a strong way to facilitate conferencing, but that their impact is sustained only insofar as they are present at court.

In some ways, the results of the present study found some conflicting themes related to knowledge, skills, and attitudes. The sample of stakeholders who were interviewed were highly 
invested in the population they served, yet they cited buy-in as a problem. They cited education as a component of the COYP's implementation, yet their main recommendation in that area was for further education. Generally, it appears that certain people (i.e., those represented in our sample) were very devoted to the needs of crossover youth and took every opportunity to learn and engage with the project. On the other hand, stakeholders suggested there was a large proportion of service providers who refused to engage with the project and did not attend educational opportunities. It is possible that those were the service providers who would have most benefitted from training. Fundamentally, projects targeting crossover youth's care need to consider that they are asking people to make behavioural changes, and market the program to those who will resist that change. Another theme, professional hierarchies and philosophies, suggests that the strategy of the CYPM (Stewart et al., 2010) - to have service providers be taught by people in their own field - may be a potentially beneficial. It may be the case that professionals trust the instructions of people within their field, who have an understanding of their training and philosophy, more than those outside it. Alternatively, opportunities to mandate participation should be taken wherever possible, as in Project Confirm (Ross et al., 2002).

Importantly, the present results indicate that - though a relatively abstract idea - changes to knowledge, skills, and attitudes, as well as culture shift, tend to persist past the end of an intervention for crossover youth. Educational events are important, but a case coordinator can also act as a resource for service providers who may have difficulty understanding what resources are available and why they are important.

To summarise, as recommended by the stakeholders, future iterations of the COYP, or similar interventions targeting crossover youth, could focus on the following: 
- Employing a full-time case coordinator in every courthouse, whose role is centered around organizing relevant stakeholders for case conferencing.

- Examining Legal Aid's current referral system for crossover youth to lawyers and developing a systemic identification and referral process to match them with two-hatter lawyers who have experience and knowledge of both the youth justice and child welfare systems.

- Strong marketing of the program considering the philosophies and opportunities for collaboration for the disparate service sectors. For example, having training conducted by someone within the service providers' fields and making it clear how the intervention can act as a resource for service providers.

- Ongoing and repeated education for the duration of the project, recognizing that the concept of crossover youth is difficult to grasp and that staff turnover necessitates repeated opportunities for service providers to engage with the project.

The present research adds to a very small body of literature on services for crossover youth and informs practices for the other sites of the COYP across Ontario, as well as future interventions for crossover youth.

\section{Limitations}

Though this study makes a significant contribution to the literature, several limitations affect the interpretability and generalizability of results. First and foremost, recruitment began at the level of the steering committee, which was composed of stakeholders who had a vested interested in the success of the program. Many had themselves been directly involved in its conceptualization and implementation. Though this meant they had very clear views of what had occurred, it also meant that they were exposed to other materials and training that were not 
available to the average stakeholder. It remains unknown how far the project reached in its efforts to educate widespread stakeholders. Similarly, because participation was voluntary in nature, the sample was self-selected. Thus, the present sample of stakeholders may represent a group who in general viewed the intervention favourably, biasing the findings of the data.

The breadth of service sectors represented in the study sample is also a shortcoming that may have introduced bias into the findings. Several stakeholder groups who commonly interact with crossover youth were not successfully recruited for interviews. These included police, probation services, and employees at the Ministry of Children and Youth Services (MCYS), as well as personnel from organizations providing addictions services, health services, and housing services. Interviewing government employees, including probation officers and the policy analysts with the MCSS required an additional level of research approvals, which we were unable to obtain after a lengthy wait because of the changing provincial government (Jenny Scott, personal communications, June 21, 2019). Interviews with some of these groups may have elucidated further difficulties in implementation of the project, as well as different philosophies that prevent a full integration of services for crossover youth. They may have also had different or opposing views on the success of the program to promote collaboration and learning.

Finally, some stakeholders asserted that there was a larger system shift occurring in youth justice and child welfare outside of the activities of the COYP. For example, stakeholders cited the new Child, Youth and Family Services Act, as well as a recent ruling by the Supreme Court (R. v. Antic) and the creation of Voluntary Youth Services Agreements. R. v. Antic was a case establishing the accused's right to bail and attainable bail conditions, unless it could be illustrated inappropriate by a crown (https://scc-csc.lexum.com/scc-csc/scccsc/en/item/16649/index.do). Voluntary Youth Service Agreements became available in 2018, 
and extended the age of protection, allowing youth to continue to receive services from child welfare until the age of 18 (Ministry of Children and Youth Services, 2018). While these are welcome and needed changes, they make it difficult to attribute changes in knowledge and attitudes to the COYP alone. Rather, the COYP itself may be the result of larger system changes acknowledging the importance of examining a youth offender's context and the vulnerability of youth in care.

\section{Future Directions}

In future research, evaluations of programs for crossover youth should not only examine how such interventions change stakeholders' degree of collaboration, knowledge, skills, and attitudes, but also how those changes affect the outcomes of youth. That is, does an increase in stakeholder collaboration, knowledge, skills, and altered attitudes actually benefit crossover youth? Outcomes to be considered should include their legal experiences (e.g., number of diversions, restrictiveness of bail conditions), but also other important areas of functioning such as school attendance and psychological symptomatology.

Of note, the current project was unsuccessful in incorporating youth for a number of reasons including: consent agreements from the project that were focused foremost on confidentiality; the timing of Time 1 interviews, such that cases had been phased out of the coordinator's care; and transience of crossover youth in general. Future research should focus on the youth's experience as stakeholders in their own care, and how they believe participation in the project and the presence of a case coordinator affected their care and outcomes. 


\section{Appendix A}

\section{Interview script - Program Outcomes - Time 1}

The purpose of this interview is for us to learn more about the Toronto site of the Crossover Youth Project (COYP) and about the services and activities provided by the COYP for crossover youth. This information will be used to assess service providers' level of satisfaction with the systems-level changes made in their communities with respect to the treatment of crossover youth and the degree to which case conferences, consultations, and resource coordination have benefited staff and crossover youth. Some questions may not be relevant to the services you provide.

Before we begin, I just want to remind you that all your answers will be confidential, and no quotes that you give us will be identified by your name, occupation, site, or any other identifying information.

Our purpose here is not to research you as an individual working in the system, but to learn about the processes and outcomes of the COYP.

Do you have any questions before we get started?

1. Please describe your role in the COYP.

2. How would you describe your experience in the COYP?

3. What changes have you observed or experienced that you can directly attribute to the COYP in the way crossover youth are treated or cared for within the various systems in which they may be involved?

Probe: in what ways has the COYP enabled the system to better address the needs of crossover youth, for example, through case conferences; better coordination of services; improved access to justice; access to "two hatter" counsel; having CAS workers at bail hearings; changes in how crossover youth may be charged by the police?

4. Has the COYP supported the rights of young people in the system in ways that were not there before?

Probe: In what ways and to what extent?

5. Has the COYP promoted youth empowerment and involvement in decision-making?

Probe: In what ways and to what extent?

6. Has the COYP promoted a greater integration of services?

Probe: If yes, in what ways and to what extent? If no, why do you think it hasn't?

7. What have been the barriers and facilitators to service integration in the work you do with crossover youth?

8. In what ways has the COYP been a resource in the work that you do with crossover youth?

Probe: in what ways has the COYP been of assistance to you (as a resource) in fulfilling your role in working with crossover youth? 
9. What are some specific ways the COYP has assisted you directly in your work with crossover youth clients?

Probe: This might include coordinating a case conference; coordinating the use of "two hatter' counsel; engaging stakeholders from different systems to share information about youth and coordinate individualized plans for youth; etc.

10. What are some specific ways the COYP has assisted you indirectly in your work with crossover youth clients?

Probe: This might include increasing your knowledge and awareness of issues facing crossover youth; changing your attitudes toward working with crossover youth; etc.

11. In what way(s) has participating in the COYP intervention changed your knowledge, skills, and attitudes toward crossover youth?

12. Has race/diversity and racism influenced the experience of staff and youth in the program?

Probe: In what ways and to what extent?

13. What recommendations would you have for improving the COYP intervention?

14. Is there anything else you wanted to mention or raise that we have not already covered?

\section{Thank you for your participation!}

For members of the Steering Committee: As part of the study, I would also like to meet with individuals in your agency or organization about their experiences with the COYP (perhaps as service providers). This would be done either by interview, as we have just done, or as a focus group. Are you able to think of individuals in your agency or organization who I might contact for this part of the study? If so, would you be able to send them this recruitment letter (hand them a copy), which I will forward to you as an electronic version? Thank you for again assistance with our study! 


\section{Appendix B}

\section{Interview script - Program Outcomes- Time 2}

The purpose of this interview is for us to learn about the impact of the Crossover Youth Project on services for crossover youth since our last interview, about 9 months ago. This information will be used to assess service providers' level of satisfaction with the systems-level changes made in their communities with respect to the treatment of crossover youth. Some questions may not be relevant to the services you provide.

Before we begin, I just want to remind you that all your answers will be confidential, and no quotes that you give us will be identified by your name, occupation, site, or any other identifying information.

Our purpose here is not to research you as an individual working in the system, but to learn about the processes and outcomes of the COYP.

Do you have any questions before we get started?

1. What changes have you observed or experienced in the past nine months that you can directly attribute to the COYP in the way crossover youth are treated or cared for?

Probe: In what ways has the COYP enabled the system to better address the needs of crossover youth, for example, through case conferences; better coordination of services; access to "two hatter" counsel; having CAS workers at bail hearings; changes in how crossover youth may be charged by the police; policy changes; the use of best practice guides?

2. Has the COYP supported the rights of young people in the system over the past nine months?

Probe: In what ways and to what extent?

3. Has the COYP promoted youth empowerment and involvement in decision-making over the past nine months?

Probe: In what ways and to what extent?

4. Has the COYP promoted a greater integration of services over the past nine months?

Probe: If yes, in what ways and to what extent? If no, why do you think it hasn't?

5. What have been the barriers and facilitators to service integration in the work you do with crossover youth over the past nine months?

6. Has the COYP been a resource in the work that you do with crossover youth over the past nine months? In what ways?

Probe: This can be direct, through the use of COYP-trained "two-hatter" counsel, or indirect, through knowledge or awareness of crossover issues.

7. In what ways have your knowledge of crossover issues, skills in working with crossover youth, and attitudes towards crossover youth changed over the past nine months? 
8. Do you believe that race and racism play a role in the systemic experiences of racialized crossover youth in your sector? Do you believe that the COYP played a role in explicitly addressing racism?

Probe: In what ways and to what extent?

9. What recommendations would you have for improving the welfare and treatment of crossover youth?

10. What changes to the treatment of crossover youth as a result of the COYP have been sustained since the withdrawal of dedicated staff from 311 Jarvis? What changes haven't been sustained?

Probe: How did it affect your ability to provide services?

11. Are you in contact with any youth who went through the program? Do you know how they are doing?

12. Is there anything else you wanted to mention or raise that we have not already covered?

\section{Thank you for your participation!}




\section{Appendix C}

\section{$\underline{\text { Stakeholder and Organizational Information Form }}$}

\section{Questions About You:}

The questions in this section of the survey ask about your current professional work.

1. What is your current position at the agency? (check one)

Executive Director

O Program Manager

O Direct Service Provider

Other, please specify

2. How many years have you been in your current position?

3. How many years of experience do you have working with youth?

4. What is your professional background? (check all that apply)

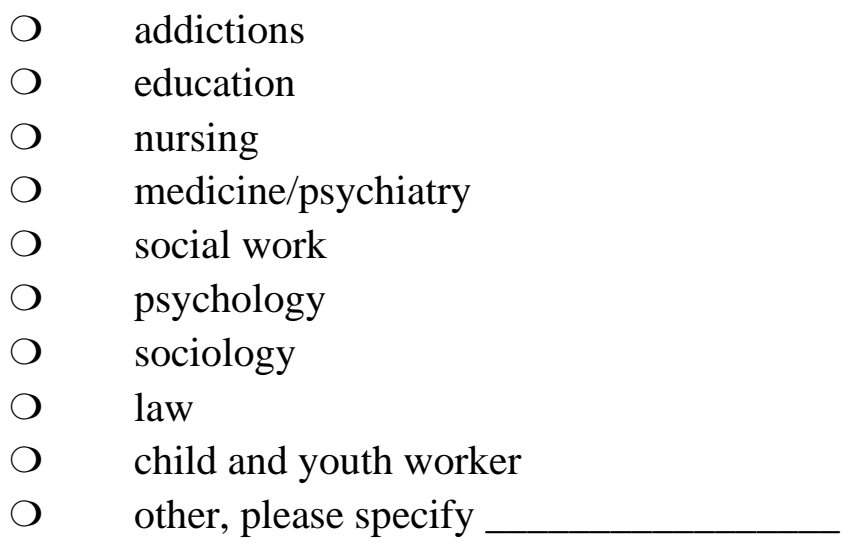

5. What is the highest level of education you have completed? (check one)
O High School diploma
O College diploma
O Bachelors degree
O Masters degree
O J.D.
O Ph.D.
Other, please specify 
6. To what extent do you influence decisions related to services for youth in your agency?

$\begin{array}{ccccccc}1 & 2 & 3 & 4 & 5 & 6 & \begin{array}{c}7 \\ \text { Not at all }\end{array} \\ & & & & & \text { Completely }\end{array}$

\section{Questions About Your Organization:}

The questions in this section of the survey ask about your organization.

7. Please indicate the primary service sector to which your organization belongs

$\begin{array}{ll}\mathrm{O} & \text { Addictions } \\ \mathrm{O} & \text { Child Welfare } \\ \mathrm{O} & \text { Children's Mental Health } \\ \mathrm{O} & \text { Health } \\ \mathrm{O} & \text { Housing/Shelter } \\ \mathrm{O} & \text { Youth Justice } \\ \mathrm{O} & \text { Other, }\end{array}$

8. Please indicate which types of services are offered by your organization (please indicate all that apply)

O Health care

O Legal services

O Assessment/Consultation

O Case management

O Outpatient treatment (non-residential treatment, usually in regularly scheduled sessions; e.g. 1-2 hours per week)

O Day treatment (intensive, structured non-residential treatment, typically provided five days a week; e.g. 3-4 hours per day)

O Inpatient/crisis beds

O Withdrawal management

O Residential treatment

O Individual therapy/counselling

O Group treatment

O Family therapy

O Recreational programs

O Housing support

O Educational programming

O Other, please specify 
9. Please indicate the age groups of the children and/or youth targeted by your organization's services (please indicate all that apply)

$\begin{array}{ll}O & 0-5 \text { years } \\ 0 & 6-11 \text { years } \\ & 12-15 \text { years } \\ & 16-20 \text { years } \\ & 20-25 \text { years }\end{array}$

10. Does your organization provide services to parents/family members?

$\begin{array}{ll}\mathrm{Y} & \text { Yes } \\ \mathrm{N} & \mathrm{No}\end{array}$

11. Describe the size of your agency: (check one)

o small ( $\leq 10$ full-time equivalent staff)

O medium (11-30 full-time equivalent staff)

- large ( $\geq 31$ full-time equivalent staff)

12. Describe your agency's academic connection (excluding your involvement with this initiative): (check one)

we work with people from a university or college

O we are in the same community as a university or college

there is no university or college in our community

other, please specify 


\section{Appendix D}

\section{$\underline{\text { Measure of Service Integration: Meeting Needs }}$}

1) My agency works collaboratively with local partners to provide services to meet the needs of my crossover youth clients.

Strongly

Disagree

1

2

3

$4-5$

5

Strongly

Agree

$6 \quad 7$

2) During the past 6 months, local partners were important in meeting the needs of my crossover youth clients.

\section{Strongly}

Disagree

1

2

3

4

5

Strongly

Agree

6 7

3) During the 6 past months I frequently had contact with people from local partners who provide services to meet the needs of my crossover youth clients.

Strongly

Disagree

1

2

3

4

5

Strongly

Agree

6

7

4) My agency influenced the services or operations of local partners to meet the needs of my crossover youth clients.

\section{Strongly}

Disagree

2

3

4

5

Strongly

Agree

6
7

5) Local partners who provide services to meet the needs of my crossover youth clients have influenced the services or operations of my agency.

\section{Strongly}

Disagree

1
2
3
Strongly

Agree
6 
6) The relationship between my agency and local partners is productive.

Strongly

Disagree

1

2

3

4

5

Strongly

Agree

6

7

7) In the past 3 months how often have you contacted each of the following cross sectoral partners?

Not at all

Addictions

Child Welfare

Children's

Mental Health

Health

Housing/Shelter

Youth Justice

Other,

$\begin{array}{ll}1 & 2 \\ 1 & 2 \\ 1 & 2\end{array}$

12

12

12

12
Somewh

at

3
3
3

3

3

3

3

3

Often

$\begin{array}{llll}4 & 5 & 6 & 7 \\ 4 & 5 & 6 & 7 \\ 4 & 5 & 6 & \end{array}$

$\begin{array}{llll}4 & 5 & 6 & 7 \\ 4 & 5 & 6 & 7 \\ 4 & 5 & 6 & 7 \\ 4 & 5 & 6 & 7\end{array}$

8) In the past 3 months how often have you been contacted by each of the following cross sectoral partners?

Not at all

Addictions

Child Welfare

Children's

Mental Health

Health

Housing/Shelter

Youth Justice

Other,

$\begin{array}{ll}1 & 2 \\ 1 & 2 \\ 1 & 2\end{array}$

3

3

3

$1 \quad 2 \quad 3$

12

12

12
Somewh

Often

at

$\begin{array}{lll}4 & 5 & 6 \\ 4 & 5 & 6 \\ 4 & 5 & 6\end{array}$

$\begin{array}{llll}4 & 5 & 6 & 7 \\ 4 & 5 & 6 & 7 \\ 4 & 5 & 6 & 7 \\ 4 & 5 & 6 & 7\end{array}$

9) In the past 3 months how often have you made referrals to each of the following cross sectoral partners?

Not at all

Addictions

Child Welfare

Children's

Mental Health

Health

Housing/Shelter
Somewh

at

3

3

3

3

3
Often

$\begin{array}{llll}4 & 5 & 6 & 7 \\ 4 & 5 & 6 & 7 \\ 4 & 5 & 6 & \\ & & & \\ 4 & 5 & 6 & 7 \\ 4 & 5 & 6 & 7\end{array}$




$\begin{array}{llllllll}\text { Youth Justice } & 1 & 2 & 3 & 4 & 5 & 6 & 7 \\ \text { Other, } & 1 & 2 & 3 & 4 & 5 & 6 & 7\end{array}$

10) In the past 3 months how often have you received referrals from each of the following cross sectoral partners?

\section{Not at all}

Addictions

Child Welfare

Children's

Mental Health

Health

Housing/Shelter

Youth Justice

Other,
Somewh

at

3
3
3

3

12

12

12

12

12
Often

$\begin{array}{llll}4 & 5 & 6 & 7 \\ 4 & 5 & 6 & 7 \\ 4 & 5 & 6 & \\ 4 & 5 & 6 & 7 \\ 4 & 5 & 6 & 7 \\ 4 & 5 & 6 & 7 \\ 4 & 5 & 6 & 7\end{array}$

11) To what extent have the referrals you have received from the following agencies been appropriate for the services your agency provides?

Not at all

$\begin{array}{llll}\text { Addictions } & 1 & 2 & 3 \\ \text { Child Welfare } & 1 & 2 & 3 \\ \text { Children's } & 1 & 2 & 3 \\ \begin{array}{l}\text { Mental Health } \\ \text { Health }\end{array} & 1 & 2 & 3 \\ \text { Housing/Shelter } & 1 & 2 & 3 \\ \text { Youth Justice } & 1 & 2 & 3 \\ \text { Other, } & 1 & 2 & 3\end{array}$

Somewh

at

$\begin{array}{lll}3 & 4 & 5 \\ 3 & 4 & 5 \\ 3 & 4 & 5 \\ 3 & 4 & 5 \\ 3 & 4 & 5 \\ 3 & 4 & 5 \\ 3 & 4 & 5\end{array}$

Often

7

7

6

$\begin{array}{ll}6 & 7 \\ 6 & 7 \\ 6 & 7 \\ 6 & 7\end{array}$

\section{Measure of Service Integration: Supporting Rights}

12) My agency works collaboratively with local partners to provide services to support the rights of my crossover youth clients.

\section{Strongly}

Disagree
1
2

3

4

5

Strongly

Agree

6 7

13) During the past 6 months, local partners were important in supporting the rights of my crossover youth clients.

\section{Strongly}

Disagree

2

3

4

5

Strongly

Agree

6

7 
14) During the 6 past months I frequently had contact with people from local partners who provide services to support the rights of my crossover youth clients.

Strongly

Disagree

1

2

3

4

Strongly

Agree

6

15) My agency influenced the services or operations of local partners to support the rights of my crossover youth clients.

\section{Strongly}

Disagree

2

3

4

5

Strongly

Agree

$6 \quad 7$

16) Local partners who provide services to support the rights of my crossover youth clients have influenced the services or operations of my agency.

Strongly

Disagree

1

$2 \quad 3$

3

45

Strongly

Agree

17) The relationship between my agency and local partners in supporting youth rights is productive.

\section{Strongly}

Disagree
2

3
Strongly

Agree

$\begin{array}{llll}4 & 5 & 6 & 7\end{array}$




\section{Appendix E}

Service Provider Adopter and Innovation Characteristics Questionnaire: Addressing Needs

Please read each of the following statements and rate each one a scale from 1 to 5 where $1=$ strongly disagree and $5=$ strongly agree

\section{Strongly}

Disagree

1

2

3

Strongly

Agree

$4 \quad 5$

\section{Adopter Characteristics}

\section{Concern}

1. I believe addressing the needs of crossover youth is very important.

2. My community should try to address the needs of crossover youth.

3. I am not certain that valuable community service resources should be directed toward the needs of crossover youth.

4. I don't know why the needs of crossover youth are important for my agency to address.

\section{Self-efficacy}

1. I can intervene effectively to address the needs of crossover youth.

2. I can ensure that the needs of crossover youth are addressed effectively in my organization.

3. I can collaborate effectively with other community agencies to address the needs of crossover youth.

4. I am not sure that I can address the needs of crossover youth effectively.

\section{Perceived Characteristics of the Innovation}

\section{Complexity}

Addressing the needs of crossover youth is difficult to do.

Strategies for addressing the needs of crossover youth are easy to understand.

Addressing the needs of crossover youth requires complex skills.

Strategies for addressing the needs of crossover youth are easy to implement.

It takes too much time to coordinate tasks and people to address the needs of crossover youth. 


\section{Compatibility}

Addressing the needs of crossover youth fits in well with my organization.

Addressing the needs of crossover youth is consistent with the work I usually do.

Addressing the needs of crossover youth reflects the values of my organization.

Addressing the needs of crossover youth does not reflect my personal values.

\section{Relative Advantage}

In general, addressing the needs of crossover youth is more effective in creating attitudes that support reintegration than our usual practices.

Addressing the needs of crossover youth is more effective in reducing problems than our usual practices.

Addressing the needs of crossover youth improves the overall quality of community services.

Addressing the needs of crossover youth is not any better than our usual practices.

\section{Service Provider Adopter and Innovation Characteristics Questionnaire: Supporting}

$\underline{\text { Rights }}$

Please read each of the following statements and rate each one a scale from 1 to 5 where $1=$ strongly disagree and $5=$ strongly agree

Strongly

Disagree

1

2

3

Strongly

Agree

45

\section{Adopter Characteristics}

\section{Concern}

1. I believe addressing the rights of crossover youth is very important.

2. My community should try to support the rights of crossover youth.

3. I am not certain that valuable community service resources should be directed toward supporting the rights of crossover youth.

4. I don't know why supporting the right of crossover youth is important for my agency to address. 


\section{Self-efficacy}

1. I can intervene effectively to support the rights of crossover youth.

2. I can ensure that the rights of crossover youth are supported effectively in my organization.

3. I can collaborate effectively with other community agencies to support the rights of crossover youth.

4. I am not sure that I can support the rights of crossover youth effectively.

\section{Perceived Characteristics of the Innovation}

\section{Complexity}

Supporting the rights of crossover youth is difficult to do.

Strategies for supporting the rights of crossover youth are easy to understand.

Supporting the rights of crossover youth requires complex skills.

Strategies for supporting the rights of crossover youth are easy to implement.

It takes too much time to coordinate tasks and people to support the rights of crossover youth.

\section{Compatibility}

Supporting the rights of crossover youth fits in well with my organization.

Supporting the rights of crossover youth is consistent with the work I usually do.

Supporting the rights of crossover youth reflects the values of my organization.

Supporting the rights of crossover youth does not reflect my personal values.

\section{Relative Advantage}

In general, supporting the rights of crossover youth is more effective in creating attitudes that support reintegration than our usual practices.

Supporting the rights of crossover youth is more effective in reducing problems than our usual practices.

Supporting the rights of crossover youth improves the overall quality of community services.

Supporting the rights of crossover youth is not any better than our usual practices. 


\section{Appendix F}

Ryerson

University

Department of Psychology

Title of Study: A formative and summative evaluation of a program for crossover youth in Toronto

Primary Investigator: Dr. David Day, Ryerson University

Co-Investigators: Dr. Tara Collins, Ryerson University, Dr. Julian Hasford, Ryerson University, Dr. Alan Leschied, Western University, Dr. Rebecca Bromwich, Carleton University, Dr. Joanna Henderson, Centre for Addiction and Mental Health

To whom it may concern:

I would like to invite you to participate in two focus groups or interviews as part of a study to evaluate the Crossover Youth Project (COYP), a program for youth who are dually-involved in the child welfare and juvenile justice systems in the Greater Toronto Area. The focus groups or interviews will be held about nine months apart, between September 2017 and May 2019. Each will last about one hour. Individual interviews may be conducted either face-to-face or by telephone.

The purpose of the focus groups is to gather information from individuals who work directly or indirectly with crossover youth, that is, youth who are dually-involved in the child welfare and juvenile justice systems. We aim to conduct focus groups or interviews with between $30-40$ key stakeholders from nine identified stakeholder groups:

- $\quad$ Police service sector

- $\quad$ Court personnel (e.g., Crown Attorney, Defence Attorney, Judges, Justices of the Peace)

- $\quad$ Probation services

- $\quad$ Relevant community agencies, such as Justice for Children and Youth (JFCY)

- $\quad$ Child welfare

- $\quad$ Relevant mental health services

- $\quad$ Members from the Ministry of Children and Youth Services (MCYS)

- $\quad$ Youth members involved in the COYP (Project C)

- Members from the group home service sector

We are interested in the views of these stakeholders and their satisfaction with the changes made in their communities with respect to the care and treatment of crossover youth as a result of the COYP. These changes may be at the systems-level (e.g., greater communication among systems), program-level (e.g., greater participation by youth in services), or practice-level (e.g., changes in the ways decisions are made about crossover youth). The questions we intend to ask study participants concern program description, program activities, program resources, and program outcomes. Sample questions are: 
1) How does the COYP promote youth empowerment and involvement in decision-making?

2) To what extent does the COYP facilitate service integration?

3) What is the impact of COYP on service provider knowledge, skills, attitudes toward the intervention and clients?

4) What are some specific ways the COYP has assisted you indirectly in your work with crossover youth clients?

The responses to these questions will be incorporated with the responses gathered in other focus groups and will be used to determine stakeholders' overall level of satisfaction with the COYP.

We will not identify any of the study participants by name or otherwise, and will keep the identity of all participants in the study confidential. We will also make a copy of our study findings available to you, if desired. The evaluation study is funded by the Law Foundation of Ontario (LFO). This study has been reviewed and approved by the Ryerson University Research Ethics Board (REB No. 2017-133).

If you are interested in participating in the study, we ask that you contact us at this email address: crossover_youth@psych.ryerson.ca (i.e., crossover "underscore” youth at psych.ryerson.ca).

Thank you very much for your time and consideration.

Sincerely,

Amy Beaudry

Research Assistant, MA Candidate

Department of Psychology

Ryerson University

On behalf of:

David M. Day, PhD, CPsych

Professor

Department of Psychology

Ryerson University 


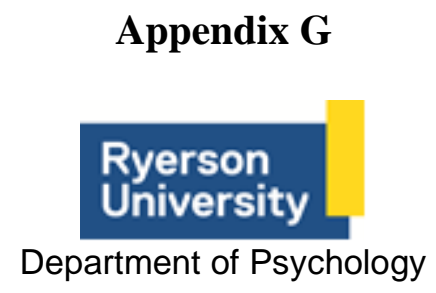

\title{
Consent to Participate in a Research Project Interview
}

Title of Study: Formative and Summative Evaluation of a Program for Crossover Youth in Toronto

\author{
David Day \\ Primary Investigator \\ Professor, Department of Psychology \\ Ryerson University \\ 350 Victoria Street \\ Toronto, ON M5B 2K3 \\ (416) 979-5000, ext. 7104 \\ dday@psych.ryerson.ca
}

You are being asked to participate in a research study. Before you give your consent to be a volunteer, it is important that you read the following information and ask as many questions as necessary to be sure you understand what you will be asked to do.

Invitation to Participate: You are being invited to participate in a research study conducted by David Day, the Principal Investigator (PI), as well as co-investigators, Dr. Tara Collins and Dr. Julian Hasford of Ryerson University, Dr. Alan Leschied of Western University, Dr. Rebecca Bromwich of Carleton University, and Dr. Joanna Henderson of the Centre for Addiction and Mental Health. Dr. Day also has several research staff working with him on this project. Their names are Dr. Arla Good and Ms. Amy Beaudry of Ryerson University. This study is being conducted as an MA thesis by Ms. Amy Beaudry under the supervision of Dr. David Day. This project is supported by a grant from the Law Foundation of Ontario (LFO).

Purpose of the Study: The purpose of the interview is to gather information from individuals who work directly or indirectly with crossover youth, that is, youth who are dually-involved in the child welfare and juvenile justice systems. Nine stakeholder groups are identified for this study, for example, the police service sector, court personnel, and probation services. We are interested in the views of stakeholders about their satisfaction about the changes made in their communities with respect to the care and treatment of crossover youth. These changes may be at the systems-level (e.g., greater communication among systems), program-level (e.g., greater participation by youth in services), or practice-level (e.g., changes in the ways decisions are made about crossover youth). This research is being completed by Ms. Amy Beaudry in partial completion of her Master's degree.

Participation: Your participation in this study will consist of two interviews, each lasting about one hour, conducted at two time periods, scheduled about nine months apart, between 2017 and 2019. At each interview, you will be asked to reflect on your professional experience working with young people in contact with the law who are also involved in the child welfare system and to discuss the changes that you have observed or experienced as a result of the COYP. The first interview will be scheduled at a time and 
location convenient to participants, between December 2017 and March 2018. All face-to-face interviews will be audio recorded.

The questions the investigators intend to ask participants will include:

1) How does the COYP promote youth empowerment and involvement in decision-making?

2) To what extent does the COYP facilitate service integration?

3) What is the impact of COYP on service provider knowledge, skills, attitudes toward the intervention and clients?

4) What are some specific ways the COYP has assisted you indirectly in your work with crossover youth clients?

The responses to these questions will be incorporated with the responses gathered from other study participants and will be used to determine stakeholders' overall level of satisfaction with the COYP.

Potential Benefits: By participating in the interview your expertise in legal or social services may assist in contributing to the development of services for crossover youth through the COYP. As well, the wider youthful offender and youth in care populations may benefit from this research in the development of services and programming to address the unique needs faced by these young people. Understanding the factors that are associated with effective and efficient services is important for the development of such programs. We cannot guarantee, however, that you will receive any benefits from participating in this study.

Risks or Discomforts: This is a minimal risk study and it is not expected that you will be put at risk by participating. While discussing the responses to the questions posed as part of the interview, you may experience some distress or discomfort. If you do, you may ask that the audio recorder be turned off (for face-to-face interviews). As well, you may, at any time, choose to decline to answer any questions posed during the session.

Confidentiality: The content of the interview will be used for the purposes of completing this research project as an MA thesis as well as related publishing in one or more research papers for scholarly journals and for presenting at scientific conferences. The data gathered during this study also may be used in future research projects. The results will be reported for the whole group and will not identify any specific individual who participated in the study. The institution/organization to which you belong will appear in a list of participants in a research report in order to demonstrate the scope /representativeness of the sample. Last, you may ask that the audio recorder to be turned off at any time you wish (for face-toface interviews).

Incentive to Participate: As an employee of an agency or organization involved in the provision of services for crossover youth, you will not receive any compensation or incentive for participating in the interview.

Conservation of Data: The data collected from this interview, that is, digital recording of the session, electronic transcripts, and written notes, will be kept in a secure manner, either stored on Dr. Day's computer, which has anti-virus software installed and a password to protect information from unauthorized access, loss, and modification, or stored in a locked cabinet in Dr. Day's lab at Ryerson University. Only the Primary Investigator and his research team will have access to these data. All data will be conserved in this manner for a period of seven years after publication of this research study at which time electronic files stored on the computer will be deleted and any written documents will be shredded. The audio recordings will be deleted once transcription is complete. 
Voluntary Nature of Participation: You are under no obligation to participate. Participation in this study is voluntary. Your choice of whether or not to participate will not influence your future relations with Ryerson University. If you decide to participate, you are free to withdraw your consent and to stop your participation at any time without penalty or loss of benefits to which you are allowed.

If you have any questions about the study, you may contact the Principal Investigator.

David Day

Professor, Department of Psychology

Ryerson University

350 Victoria Street

Toronto, ON M5B 2K3

(416) 979-5000, ext. 7104

dday@psych.ryerson.ca

This study has been reviewed by the Ryerson University Research Ethics Board. If you have questions regarding your rights as a participant in this study please contact:

Research Ethics Board

c/o Office of the Vice President, Research and Innovation

Ryerson University

350 Victoria Street

Toronto, ON M5B 2K3

416-979-5042

rebchair@ryerson.ca 


\section{Agreement:}

Your signature below indicates that you have read the information in this agreement and have had a chance to ask any questions you have about the study. Your signature also indicates that you agree to be in the study and have been told that you can change your mind and withdraw your consent to participate at any time. You have been given a copy of this agreement. You have been told that by signing this consent agreement you are not giving up any of your legal rights.

Note: There are two copies of this consent form, one of which is yours to keep.

Participant's Signature

Date

Your signature below indicates that you agree to being audio recorded.

Participant's Signature

Interviewer's Signature Date

Do you agree to be contacted by a research assistant to participate in a follow-up interview as part of this research?

Yes $\square \quad$ No 
Receive a summary of the results

Yes, please send me a summary of the results!

Name:

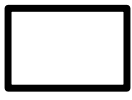

Email Address:

Mailing Address (optional): 


\section{References}

Armstrong, D., Gosling, A., Weinman, J., \& Marteau, T. (1997). The place of inter-rater reliability in qualitative research: An empirical study. Sociology, 31, doi: 10.1177 /0038038597031003015

Baetz, C. (2017). A long-term follow-up of crossover youth: Young adult outcomes for maltreated youths in the juvenile justice system (Doctoral dissertation). Retrieved from ProQuest Dissertations and Theses database. (UMI No. 3729076)

Baglivio, M. T., Wolff, K. T., Piquero, A. R., Bilchik, S., Jackowski, K., Greenwald, M. A., \& Epps, N. (2016). Maltreatment, child welfare, and recidivism in a sample of deep-end crossover youth. Journal of Youth and Adolescence, 45, 625-654. doi: 10.1007/s10964015-0407-9

Bala, N., Finlay, J., De Filippis, R., \& Hunter, K. (2015). Child welfare adolescents \& the youth justice system: Failing to respond effectively to crossover youth. Canadian Criminal Law Review, 19, 129-151.

Braun, V., \& Clarke, V. (2006). Using thematic analysis in psychology. Qualitative Research in Psychology, 3, 77-101. doi: 10.1191/1478088706qp063oa

Chaim, G., \& Henderson, J. (2017). National Youth Screening Project: Part Two. Putting the 'Youth' in Youth-Focused Services: A focus on developmentally-informed care. Margaret and Wallace McCain Centre for Child, Youth and Family Mental Health. Retrieved from: https://eenet.ca/sites/default/files/pdfs/NYSP\%20Developmentally \%20Informed\%20Care\%20Report_1.pdf 
Chapin, D. A., \& Griffin, P. A. (2005). Juvenile diversion. In K. Heilbrun, N. Goldstein, \& R. Redding (Eds.), Juvenile delinquency: Prevention, assessment, and intervention (pp. 161178). New York, NY: Oxford University Press.

Conger, D., \& Ross, T. (2001). Reducing the foster care bias in juvenile detention decisions. Retrieved from Vera Institute of Justice website: https://www.vera.org/publications /reducing-the-foster-care-bias-in-juvenile-detention-decisions-the-impact-of-projectconfirm

Conger, D., \& Ross, T. (2006). Project Confirm: An outcome evaluation of a program for children in the child welfare and juvenile justice systems. Youth Violence and Juvenile Justice, 4, 97-115. doi: 10.1177/1541204005282314

Creswell, J. W. (2014). Research design: Qualitative, quantitative, and mixed method approaches $\left(4^{\text {th }}\right.$ ed.). Thousand Oaks, CA: SAGE Publications.

Cross-over Youth Project. (2016). Developing model: Downtown Toronto components. Retrieved from Cross-over Youth Project website: http://crossoveryouth.ca/wp-content/uploads /2016/03/COY-Developing-Model-Downtown-Toronto-FINAL.pdf

Day, D., Bromwich, R., Collins, T., Hasford, J., Henderson, J., \& Leschied, A. (2016). An evaluation of the Cross-over Youth Project (COYP). Proposal to the Law Foundation of Ontario.

Dishion, T. J., \& Dodge, K. A. (2005). Peer contagion in interventions for children and adolescents: Moving towards an understanding of the ecology and dynamics of change. Journal of Abnormal Child Psychology, 33, 395-400. doi: 10.1007/s10802-005-3579-z 
Eastman, A. L., \& Putnam-Hornstein, E. (2018). Exit outcomes for probation-supervised youth in foster care: An examination of past child protection involvement. Child Maltreatment, 23, 34-43. doi: $10.1177 / 1077559517718956$

Fallon, B., Van Wert, M., Trocmé, N., MacLaurin, B., Sinha, V., Lefebvre, R.,...Goel, S. (2015). Ontario Incidence Study of Reported Child Abuse and Neglect-2013 (OIS-2013). Retrieved from Child Welfare Research Portal website: http://cwrp.ca/sites/default/files /publications/en/ois-2013_final.pdf

Farineau, H. M., \& McWey, L. M. (2011). The relationship between extracurricular activities and delinquency of adolescents in foster care. Children and Youth Services Review, 33, 963-968. doi: 10.1016/j.childyouth.2011.01.002

Farrell, J. L., Young, D. W., \& Taxman, F. S. (2011). Effects of organizational factors on use of juvenile supervision practices. Criminal Justice and Behavior, 6, 565-583. doi: $10.1177 / 0093854811401786$

Finlay, J. (2007). We are your sons and daughters: The Child Advocate's report on the quality of care of 3 Children's Aid Societies. Retrieved from Kawartha-Haliburton Children's Aid Society website: https://www.khcas.on.ca/treatmentfostercare/wp-content/uploads /sites/18/2016/03/We-are-Your-Sons-and-Daughters.pdf

Finlay, J. (2012). Keeping kids safe in custody. In A. Westhues \& B. Wharf (Eds.), Canadian social policy: Issues and perspectives (pp. 253-71). Waterloo, ON: Wilfrid Laurier University Press.

Flick, U. (2014). An introduction to qualitative research (5 $5^{\text {th }}$ ed.). Thousand Oaks, CA: SAGE Publications. 
Gallegos, A. H. \& Roller White, C. (2007). Preventing the school-justice connection for youth in foster care. Family Court Review, 51, 460-468.

Haight, W., Bidwell, L., Choi, W. S., \& Cho, M. (2016). An evaluation of the Crossover Youth Practice Model (CYPM): Recidivism outcomes for maltreated youth involved in the juvenile justice system. Children and Youth Services Review, 65, 78-85. doi: 10.1016/j.childyouth.2016.03.025

Haight, W. L., Bidwell, L. N., Marshall, J. M., \& Khatiwoda, P. (2014). Implementing the Crossover Youth Practice Model in diverse contexts: Child welfare and juvenile justice professionals' experiences of multisystem collaborations. Children and Youth Services Review, 39, 91-100. doi: 10.1016/j.childyouth.2014.02.001

Halemba, G. J., Siegel, G. C., Lord, R. D., \& Zawacki, S. (2004). Arizona dual jurisdiction study: Final report. Retrieved from National Center for Juvenile Justice website: http://www.ncjj.org/pdf/azdual_juri.pdf

Henderson, J. L. (2003). Factors affecting adoption and implementation of a community-based children's mental health program: The TAPP-C example (Doctoral dissertation). Retrieved from ProQuest Dissertations and Theses database.

Henderson, J. L., MacKay, S., \& Peterson-Badali, M. (2006). Closing the research-practice gap: Factors affecting adoption and implementation of a children's mental health program. Journal of Clinical Child and Adolescent Psychology, 35, 2-12. doi: 10.1207 /s15374424jccp3501_1

Henderson, J. L., MacKay, S., \& Peterson-Badali, M. (2010). Interdisciplinary knowledge translation: Lessons learned from a mental health: Fire service collaboration. American Journal of Community Psychology, 46, 277-288. doi: 10.1007/s10464-010-9349-2 
Herz, D. C., Ryan, J. P., \& Bilchik, S. (2010). Challenges facing crossover youth: An examination of juvenile-justice decision making and recidivism. Family Court Review, 48, 305-321. doi: 10.1111/j.1744-1617.2010.01312.x

Horwath, J. \& Morrison, T. (2007). Collaboration, integration and change in children's services: Critical issues and key ingredients. Child Abuse \& Neglect, 31, 55-69. doi: 10.1016/j.chiabu.2006.01.007

Hoult, M. (2012, December 5). Rising number of calls from group, foster homes. Community Press. Retrieved from http://www.communitypress.ca

Huang, H., Ryan, J. P., \& Herz, D. (2012). The journey of dually-involved youth: The description and prediction of rereporting and recidivism. Child and Youth Services Review, 34, 254-260. doi: 10.1016/j.childyouth.2011.10.021

Huang, H., Ryan, J. P., Sappleton, A., \& Chiu, Y. (2015). Crossover youth post arrest: Placement status and recidivism. Children and Youth Services Review, 57, 193-200. doi: 10.1016/j.childyouth.2015.08.015

Irvine, A., \& Canfield, A. (2016). The overrepresentation of lesbian, gay, bisexual, questioning, gender nonconforming and transgender youth within the child welfare to juvenile justice crossover population. Journal of Gender, Social Policy \& the Law, 24, 243-261.

Jones, A., Sinha, V., \& Trocmé, N. (2015). Children and youth in out-of-home care in the Canadian provinces (CWRP Information Sheet \#167E). Retrieved from Centre for Research on Children and Families: http://cwrp.ca/sites/default/files/publications/en /167e.pdf 
Kolivoski, K. M., Goodkind, S., \& Shook, J. J. (2017). Social justice for crossover youth: The intersection of the child welfare and juvenile justice systems. Social Work, 62, 313-321. doi: 10.1093/sw/swx034.

Lee, S., \& Villagrana, M. (2015). Differences in risk and protective factors between crossover and non-crossover youth in juvenile justice. Children and Youth Services Review, 58, 1827. doi: 10.1016/j.childyouth.2015.09.001

Malakieh, J. (2017). Youth correctional statistics in Canada. Retrieved from Statistics Canada website: http://www.statcan.gc.ca/pub/85-002-x/2017001/article/14702-eng.pdf

MacPhail, C., Khoza, N., Abler, L., \& Ranganthan, M. (2016). Process guidelines for establishing Intercoder Reliability in qualitative studies. Qualitative Research, 16, 198212. doi: $10.1177 / 1468794115577012$

Ministry of Children and Youth Services. (2018). Protection services for 16- and 17-year olds: Information for Youth. Retrieved from: http://www.children.gov.on.ca/htdocs/English /professionals/childwelfare/information_for_youth_protection_services_EN.pdf

Moffitt, T. E. (1993). Adolescence-limited and life-course-persistent antisocial behavior: A developmental taxonomy. Psychological Review, 100, 674-701. doi: 10.1037/0033295X.100.4.674

Piscitelli, A., \& Follett, K. (2012). From one system to another: Crossover children in Waterloo region. Retrieved from Waterloo Region Crime Prevention Council: http:/ /preventingcrime.ca/wp-content/uploads/2014/08/2012-CrossoverChildreninWR.pdf

Ross, T., Conger, D., \& Armstrong, M. (2002). Bridging child welfare and juvenile justice: Preventing unnecessary detention of foster children. Child Welfare, LXXXI, 471-494. 
Ryan, J. P., Herz, D., Hernandez, P. M., \& Marshall, J. M. (2007). Maltreatment and delinquency: Investigating child welfare bias in juvenile justice processing. Children and Youth Services Review, 29, 1035-1050. doi: 10.1016/j.childyouth.2007.04.002

Ryan, J. P., \& Testa, M. F. (2005). Child maltreatment and juvenile delinquency: Investigating the role of placement and placement instability. Children and Youth Services Review, 27, 227-249. doi: 10.1016/j.childyouth.2004.05.007

Scully, B., \& Finlay, J. (2015). Cross-over youth: Care to custody. Retrieved from Crossover Youth website: http://crossoveryouth.ca/wp-content/uploads/2016/03/Cross-OverYouth_Care-to-Custody_march2015.pdf

Stewart, A., Dennison, S., \& Waterson, E. (2002). Pathways from child maltreatment to juvenile offending. Retrieved from Criminology Research Grants website: http://www .criminologyresearchcouncil.gov.au/reports/stewart.pdf

Stewart, B. (2018). Crossover kids: Maltreatment experiences, subsequent maladjustment, and systems of care. Unpublished Masters Thesis, University of Western Ontario, London, Ontario.

Stewart, M., Lutz, L., \& Herz, D. (2010). Crossover Youth Practice Model. Washington, DC: Center for Juvenile Justice Reform, Georgetown University McCourt School of Public Policy.

Stouthamer-Loeber, M., Wei, E. H., Homish, D. L., \& Loeber, R. (2002). Which family and demographic factors are related to both maltreatment and persistent serious juvenile delinquency? Children's Services: Social Policy, Research, and Practice, 5, 261-272. doi: 10.1207/S15326918CS0504_3 
Tam, C. C., Abrams, L. S., Freisthler, B., \& Ryan, J. P. (2016). Juvenile justice sentencing: Do gender and child welfare involvement matter? Child and Youth Services Review, 64, 6065. doi: 10.1016/j.childyouth.2016.02.028

Turpel-Lafond, M., \& Kendall, P. (2009). Kids, crime and care - Health and well-being of children in care: Youth justice experiences and outcomes. Retrieved from Representative for Children and Youth website: https://www.rcybc.ca/sites/default/files/documents/pdf /reports_publications/kids_crime_and_care.pdf

Vidal, S., Prince, D., Connell, C. M., Caron, C. M., Kaufman, J. S., \& Tebes, J. K. (2017). Maltreatment, family environment, and social risk factors: Determinants of the child welfare to juvenile justice transition among maltreated children and adolescents. Child Abuse \& Neglect, 63, 7-18. doi: 10.1016/j.chiabu.2016.11.013

Widom, C. S. (1989). The cycle of violence. Science, 244, 160-166. doi: 10.1126/science .2704995 